\title{
Propuesta Simbiótica Natural-Cultural en Territorio Mapuche de
} Arauco

\section{Natural-Cultural Symbiotic Proposal in the Mapuche Territory of Arauco}

\author{
Mario López ${ }^{1,2}$, Andrea Valenzuela ${ }^{1}$, Claudio Carrasco ${ }^{1}$
}

\begin{abstract}
Resumen
Esta investigación evalúa las formas de ocupación en el territorio mapuche y sus procesos de transformación en la comuna de Arauco. La hipótesis plantea que se ha perdido la relación simbiótica natural-cultural entre el mapuche y su entorno. La metodología consistió en la caracterización del paisaje de manera cualitativa y cuantitativa en el contexto del grupo indígena, partiendo con 39 indicadores de primera generación, asignados y creados a la medida. Luego se formaron 8 componentes principales o indicadores de segunda generación, representando un área de análisis multidimensional, para luego ser agrupados nuevamente y formar un indicador de tercera generación o Índice de Sustentabilidad del Paisaje de Arauco (ISPA). Cada indicador fue jerarquizado dentro de su componente por medio del Proceso de Análisis Jerárquico (PAJ), resultando una cifra única para entender el estado de sustentabilidad de la comuna analizada en 4 períodos de tiempo (Siglo XVI, Siglo XVII, 1960 y 2016). El análisis de la información evidencia una pérdida de la condición simbiótica natural-cultural. Por último, se realiza la propuesta de una imagen objetivo, llevada a cabo con una sistematización de los resultados y la percepción actual de las comunidades mapuches por medio de talleres y entrevistas donde se graficó el esquema de una unidad comunitaria mínima para un territorio cuantificado por hectáreas y porcentajes promediados según los resultados. La propuesta se enfoca en la visión y recuperación del territorio para lograr la Sustentabilidad del Paisaje Mapuche.
\end{abstract}

Palabras clave: Paisaje Mapuche, Simbiosis Natural-Cultural, Sustentabilidad del Paisaje.

\begin{abstract}
This investigation evaluates the manner in which the Mapuche occupy their territory and follows its transformational process in the Arauco Commune. The hypothesis seeks to determine if the Mapuche people have lost a natural-cultural symbiotic relationship with their environment. The applied methodology focuses on the characterization of the landscape in a qualitative and quantitative manner per the indigenous group's context, beginning with 39 indicators of first generation, which were assigned and custom created. The study also included 8 main components or second generation indicators, representing a multidimensional analysis area, which were regrouped again to create a third generation indicator or Arauco Landscape Sustainability Index (ISPA). Each indicator was weighed against its components through the Hierarchical Analysis Process (PAJ), resulting with a single number to understand the commune sustainability situation, assessed in 4 periods of time (Century XVI, XVII, year 1960 and 2016). The analysis of the information proves a loss in the natural-cultural symbiotic relation. The final part of this work was the creation of a proposal of the ideal image, achieved with a systematization of the results and the current perception of the Mapuche communities through workshops and interviews. This allowed for an elaboration of a minimum community unity scheme for a quantified territory in hectares and averaged percentages. The proposal focus on the territory vision and recovery to achieve the Sustainability of the Mapuche Landscape.
\end{abstract}

Keywords: Mapuche Landscape, Natural-Cultural Symbiosis, Landscape Sustainability

Recibido el 03 de julio de 2017, aceptado el 27 de octubre de 2017.

\footnotetext{
1 Facultad de Arquitectura, Universidad de Valparaíso, Valparaíso, Chile. Avda. Parque 570, Valparaíso. Email: mario.lopezh@postgrado.uv.cl

2 Fundación Hábitat para la Humanidad Guatemala. Email: mjlopez@habitatguate.org
} 


\section{Introducción}

\section{Planteamiento del problema}

El progreso del ser humano no se mantiene en una sola vía, sino que se desenvuelve en una constante y compleja interacción natural-cultural, como un proceso vivo en el tiempo, en búsqueda permanente de equilibrio, cuyas interrelaciones son de carácter simbiótico (Margulis, 1998), este conocimiento nace en escala local, vinculada al entorno que se habita, por lo que es parte del acervo con que muchos pueblos originarios se han identificado para poder vivir (Aj Xol Ch'ok, 2008; Arguedas, 1958; Asturias, 1974; Fuentes, 2003; Paz, 1950). En este caso de estudio, considerando al Pueblo Mapuche, la hipótesis plantea que la manera en la que se percibía el territorio, pudo haber sido por medio de una relación metafísica con el entorno, desarrollando una estrategia cercana a una simbiosis natural-cultural, una filosofía que habita de manera dual con el entorno, entendiendo que la tierra es su alimento y que por lo tanto se le debe respeto en el manejo de ella (figura 1). La investigación también presenta una segunda hipótesis, que surge al contextualizar la realidad mapuche en la actualidad, postulando que el impacto recibido en su territorio, a través de los distintos períodos de ocupación extranjera, ha generado una pérdida de la sustentabilidad y de esa misma condición simbiótica natural-cultural, acarreada por acciones como la explotación del suelo, pérdida del patrimonio, sustitución del bosque nativo, alteración cultural, entre otros (figura 2)

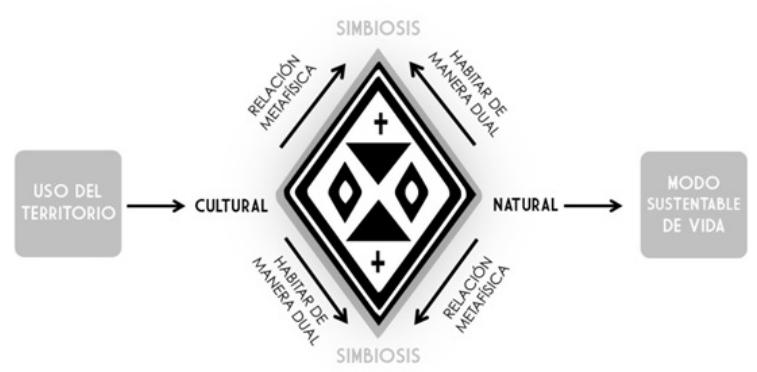

Figura 1. Hipótesis 1. Fuente: Elaboración propia en base a Micelli \& Crespo (2011)

Figure 1. Hypothesis 1. Source: Own elaboration based on Micelli \& Crespo (2011)

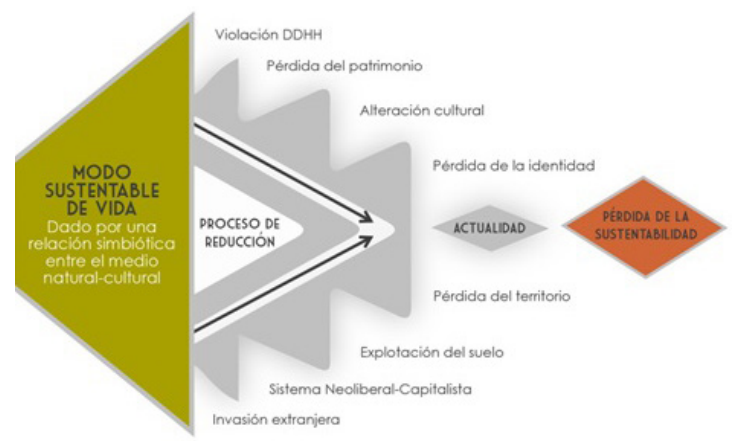

Figura 2. Hipótesis 2. Fuente: Elaboración propia en base a Micelli \& Crespo (2011)

Figure 2. Hypothesis 2. Source: Own elaboration based on Micelli \& Crespo (2011) 
Antecedentes sobre el pueblo mapuche

La Cultura Mapuche representa un pueblo originario de la zona centro sur de Chile y Argentina, con una historia que ha sido documentada por registros arqueológicos cercanos a los 4.000 años de antigüedad (Bengoa, 2007; Ugent et al., 1987). De la información proveniente de esta cultura, se sabe que para el Siglo XVI habían logrado un desarrollo político, económico y social en una vasta extensión de territorio, con una población mayor al millón de habitantes y un contexto caracterizado por su organización y prácticas vinculadas al medio natural (Zavala \& Dillehay, 2010). Sin embargo, luego de la venida de los españoles, enfrentarían un proceso de pérdida de su medio natural y cultural. Si a un principio su preocupación eran los peninsulares (Casanova, 1987; Goicovich, 2002), más adelante el conflicto sería con el Estado de Chile y sus distintos métodos en la búsqueda de la reducción de esta cultura con la introducción de colonos y la fragmentación de las comunidades a reducciones (Díaz, 2010; Gavilán, 2007). Este escenario se repetiría durante varios siglos (XIX, XX), en el período de la dictadura militar (Gutiérrez, Puentes, \& Reyes, 2012; Rosenblitt \& Nazer, 2005), y de la promulgación de leyes que no daban lugar al reconocimiento de ningún pueblo originario (Caniuqueo, 2013; Chihuailaf, 1999; Correa, Molina y Yánez, 2005; Merguier, 1989). Más adelante, con el ingreso de la Concertación, la emisión de nuevas leyes y nuevos programas a nivel nacional serían prácticas que no solventarían el problema de manera profunda (Gazmuri, 2013; Navarro, 1998).
Actualmente, no se reconoce el impacto cultural en el paradigma mapuche (Díaz, Pérez, González y Simon, 2004; Garrido, 1998; Martínez, 2013; TorresSalinas et al., 2016; Carrasco 2015), en respuesta a ello, se ejecutan distintos métodos y prácticas para la restitución de su territorio ancestral (Mella, 2007), muchos por la vía pacífica en temas legales y con apoyo internacional, otros en cambio, con métodos más agresivos, sin tener solución a un conflicto que ha dejado pérdidas materiales y humanas (Pairican, 2014). Al analizar esta coyuntura, surgen las interrogantes sobre el enfoque que este camino debiera tomar y en este contexto es que toma pertinencia y vinculación para esta investigación, pues busca entender el territorio y conocer de qué manera se debiera utilizar el medio natural (Carrasco \& Murtinho, 2016).

\section{Escalas organizacionales del espacio mapuche}

La concepción espiritual para los mapuches sobre su territorio es de una manera cíclica ligada a la morfología de la tierra (Chihuailaf, 1999), el centro se considera sagrado, con la colocación del Rewe, altar sagrado para distintas ceremonias, consiste en un tronco escalonado clavado en el suelo rodeado de plantas de Canelo (Drymis winteri). En ocasiones tiene la representación de un rostro humano simbolizando el centro del universo (Huenún, 2013; Mora, 2001; Dowling, 1971). La posición del Rewe también se definía al percibir la presencia de un Ngen, como lo cita María Ester Grebe (Moulian \& Gonzalez, 2005) (Ver figura 3). 


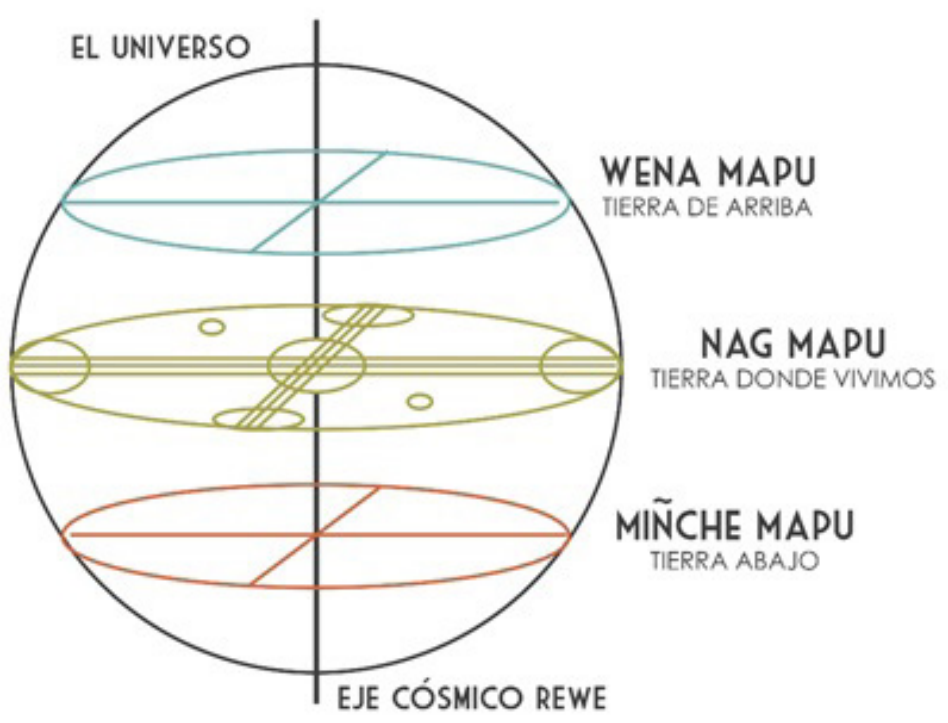

Figura 3. Filosofía Mapuche sobre la Concepción del Territorio. Fuente: Elaboración propia en base a Chihuailaf (1999)

Figure 3. Mapuche Philosophy about the Conception of the Territory. Source: Own elaboration based on Chihuailaf (1999)

Esta representación espiritual también ocurre en el lenguaje (Mapudungun = el hablar de la tierra) fundado sobre la palabra hablada, que en este aspecto se refiere, no a la materia del suelo sino al paisaje o territorio, como lo define Heidegger (2008, p. 67) "El hombre histórico funda sobre la tierra su morada en el mundo. Al establecer la obra un mundo, hace la tierra"

Los mapuches concebían las divisiones del territorio como limes, que hace referencia a la cuenca hidrográfica como unidad de paisaje, creando condiciones naturales para su desarrollo ecosistémico en los límites de su morfología (Goicovich, 2004), percibidas como verdaderas rutas de integración entre las unidades parentales involucradas en la dinámica de las relaciones intra-étnicas.

La cantidad de territorio ocupada dependía del crecimiento de una comunidad, el cual principia con el Lov o Lof, que es la familia (Lofche, Grupo de gente). En numerosos grupos de familia se conformaba un Lebo o comunidad, delimitado por cuerpos de agua, ya sean caudales o ríos, empleados como fuentes de recursos para la pesca, agricultura y conectividad desde la cordillera hacia el mar, permitiendo ser navegables con canoas monóxilas en ambas direcciones (Carabias, Lira y Adán, 2010, Núñez et al., 1994)

El modelo de asentamiento se pudo replicar desde el río Itata hacia el Río Toltén según Torres (2003), donde existían las condiciones de un medio ambiente natural suficiente para permitir el desarrollo cultural. Partiendo de los límites geográficos que representaban límites políticos, se entiende la organización a nivel de sub-cuencas, como una organización local; cuencas, como el conjunto de varios lebos o Aillarewe, Ailla, nueve, rewes, comunidades, concepto de agrupamiento de comunidades; y macro-cuencas, dadas por conexiones logradas en distintos territorios que en este caso será determinado: El Territorio Mapuche (Bengoa, 2007). 
Para el cultivo, conectividad y clasificación del suelo, se realizaban modificaciones geomorfológicas tales como el Kuel, monumento del tipo montículo construido con la finalidad de lograr diferentes propósitos, como el entierro de personajes importantes, ceremonias mortuorias y religiosas, residenciadelasélitesyexhibición pública de poder (figura. 4). Los Kuel permitían un mejor nivel de organización social ante el crecimiento demográfico. En esos espacios la "naturaleza, sociedad y cultura se mezclaban, o una se volvía la extensión de la otra" (Dillehay, 2011, p.107). Los Kuel o Rewekuel (agrupación de montículos para distintos usos), eran construidos para representar la extensión cultural de lo natural (figura. 5)

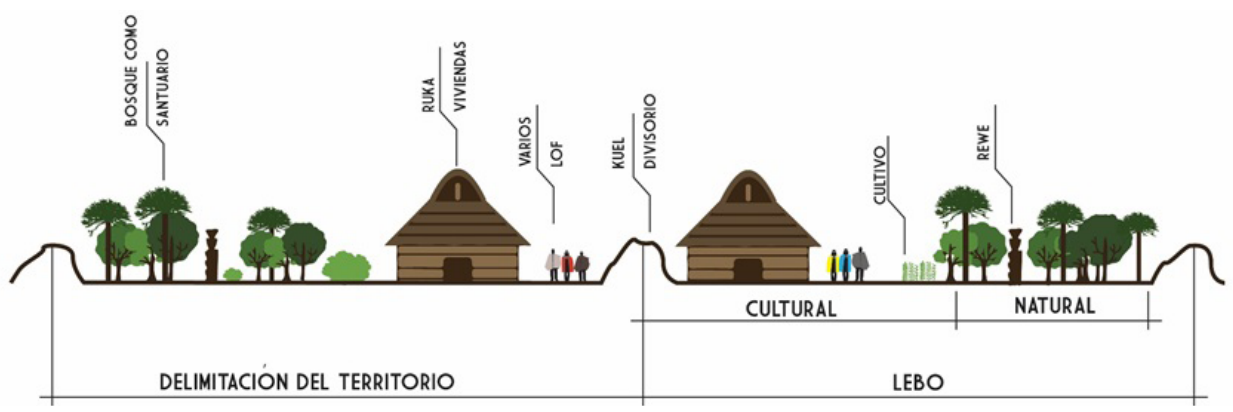

Figura 4. Usos posibles del Kuel. Fuente: Elaboración Propia con base a teoría de Dillehay (2011)

Figure 4. Kuel possible uses. Source: Own elaboration based on Dillehay (2011)

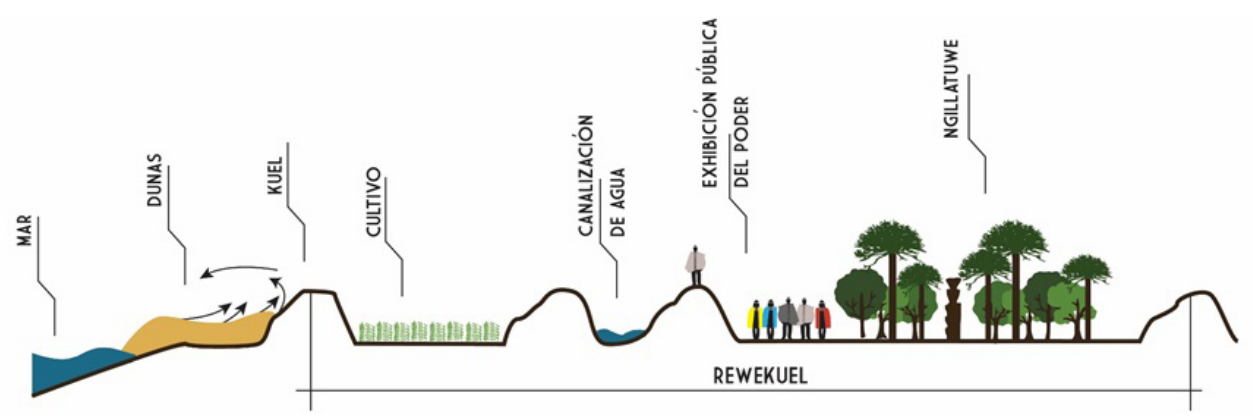

Figura 5. Rewekuel. Fuente: Elaboración Propia con base a teoría de Dillehay (2011)

Figure 5. Rewekuel. Source: Own elaboration based on Dillehay (2011)

\section{Arauco en la actualidad}

La comuna de Arauco es una zona geográfica poblada desde hace más de 4.500 años (Bustos \& Vergara, 2004), siendo de gran importancia para los pueblos originarios debido a la condición de bahía y hogar de extensos humedales. Entre los conflictos territoriales presentes se encuentra la introducción del cultivo forestal que degrada los ecosistemas naturales (Huber \& Trecaman, 2000; Huber \& Trecaman, 2004; Iroumé \& Palacios, 2013), alterando el bosque nativo obligándolo a retroceder y fraccionarse, elevando los índices de erosión por daños antrópicos, ocasionando efectos como la escorrentía elevada, alta probabilidad de incendios, reducción de 
la biodiversidad y de regeneración natural (Quintanilla \& Morales, 2004).

Se evidencian impactos en la población rural debido a la pobreza que genera esta actividad agrícola (Nazif, Benavides y Pizarro, 2014), y las secuelas culturales en la población mapuche (Seguel, 2003). Actualmente un $80 \%$ del suelo de Arauco es para cultivos forestales. A falta de un plan de manejo o una directriz sobre la sustentabilidad del paisaje han reducido al bosque nativo a un área menor al $2 \%$ de la comuna. Las repercusiones de un cultivo forestal extensivo sobre el territorio de Arauco han ocasionado un déficit hídrico en los últimos años (Huber, Iroumé, Mohr y Frenê, 2010), a pesar de ser una zona que recibe altas precipitaciones durante el año (Dirección General de Aguas, 2011).

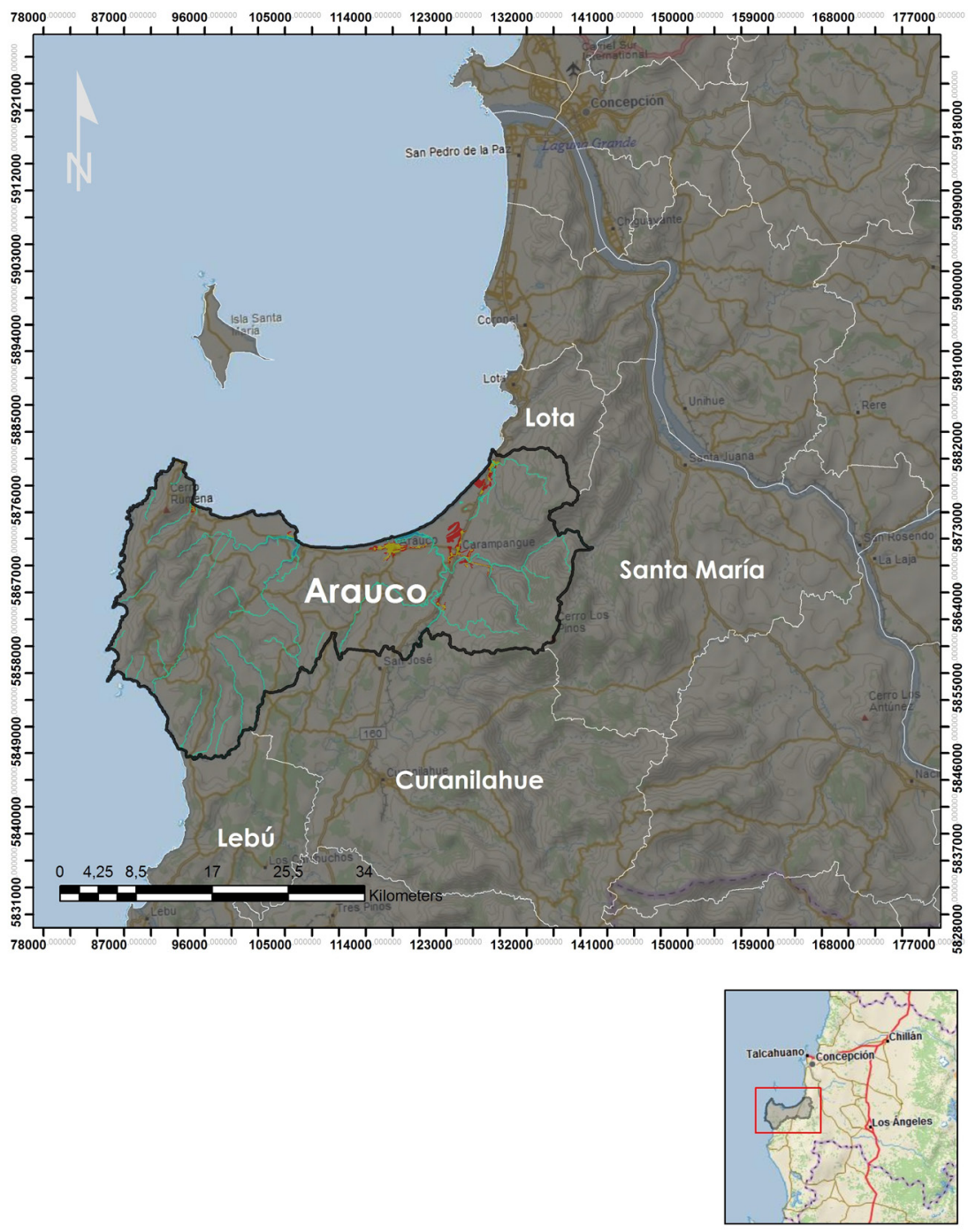

Figura 6. Localización de la comuna de Arauco. Fuente: Elaboración propia (2017)

Figure 6. Arauco commune location. Source: Own elaboration (2017) 


\section{Materiales y métodos}

La metodología de investigación fue propuesta con la finalidad de tener una lectura del paisaje mapuche medible y comparable empleando el concepto de sustentabilidad del paisaje, definido por 4 pilares de trabajo según Sharifi \& Murayama (2012) en sus maneras de evaluar el territorio a escala de barrio: 1. Ambiental (medio natural de interacción) 2. Social (identidad mapuche local.) 3. Económico (actividades, intercambio y diversidad productiva) y 4. Institucional (concepción y organización del buen gobernar, cuidado del patrimonio). Con este enfoque se escogieron instrumentos de medición que tuvieran coherencia hacia cada pilar. Primero, con indicadores de análisis general del paisaje tales como: calidad de aire, agua disponible en la cuenca, suelos con impactos antropogénicos, biomasa, fragmentación de áreas boscosas, conectividad, pobreza, entre otros, consultados en fuentes como Schuschny \& Soto (2009), RaceroCasarrubia (2008), Rueda (2008). Luego se diseñaron indicadores sintéticos en base a la técnica encontrada en Canales (2006), para medir los aspectos culturales mapuches, tales como la participación en el Trafkintu (actividad económica que consiste en el intercambio de semillas y otros productos) (Colipán, 2008), Cumplimiento del Az Mapu (Conjunto de leyes establecidas en la cosmovisión mapuche para su cumplimiento común) (Sánchez, 2001), eficiencia en métodos de defensa (Mella, 2007), entre otros. En la figura 7 se presenta la tabla con los 39 indicadores propuestos para analizar el Paisaje de Arauco.

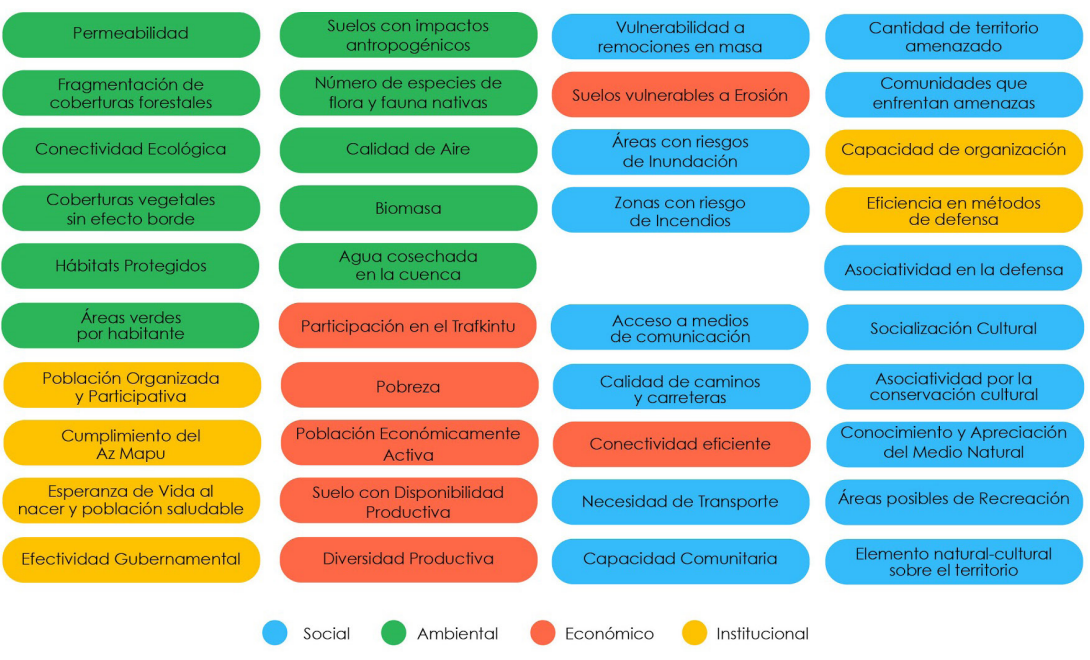

Figura 7. Listado de 39 indicadores para el análisis del paisaje de Arauco. Fuente: Elaboración Propia (2017)

Figure 7. List of the 39 indicators for the Arauco landscape analysis. Source: Own elaboration (2017)

Debido al elevado número de indicadores, se clasificaron en base a su categoría de primera, segunda o tercera generación como lo explica Quiroga (2007). Los de primera, son indicadores que generan datos específicos sobre un área de estudio, por lo que pueden ser parciales y no representan un análisis complejo, a este grupo pertenecen los 39 ya enumerados (figura 7). Los de segunda generación tienen un enfoque multidimensional, cada uno representanta uno de los pilares de la sustentabilidad. 
Para este caso se consideraron 4 indicadores de segunda generación propuestos por Carrasco et al. (2013) que incluyen $20 \mathrm{de}$ los 39 citados.

Partiendo de esta forma de agrupación, afín a un área multidimensional del paisaje, se agruparon los 19 indicadores restantes para lograr 4 indicadores más de segunda generación, enfocados en el análisis de los aspectos culturales mapuches.

Cada indicador primario representa una cifra entre 0 y 1 , para lograr lo mismo en un indicador secundario era necesario unificar los instrumentos en un método de multi-criterio como el Proceso de Análisis Jerárquico (PAJ) propuesto por
Saaty (2008) que en el caso de Carrasco et al. (2013) estaban establecidos en los instrumentos previos (figura 8 y 9). La tabla 1 muestra como un ejemplo, el contenido del indicador secundario Cuidado del Paisaje (CP), analizando la importancia de un indicador primario por encima de otro, con una valoración desde 7, 5, 3 y 1, donde 7 es mucho más importante y 1 es igual de importante. La normalización se realiza para dar un porcentaje final de importancia en el indicador de segunda generación. Luego se presenta la ecuación, que multiplica el valor del indicador primario (abreviado) con el porcentaje de importancia que fue normalizado ( $\%$ entre 0 y 1 ), dando como resultado una cifra entre 1 y 0 .
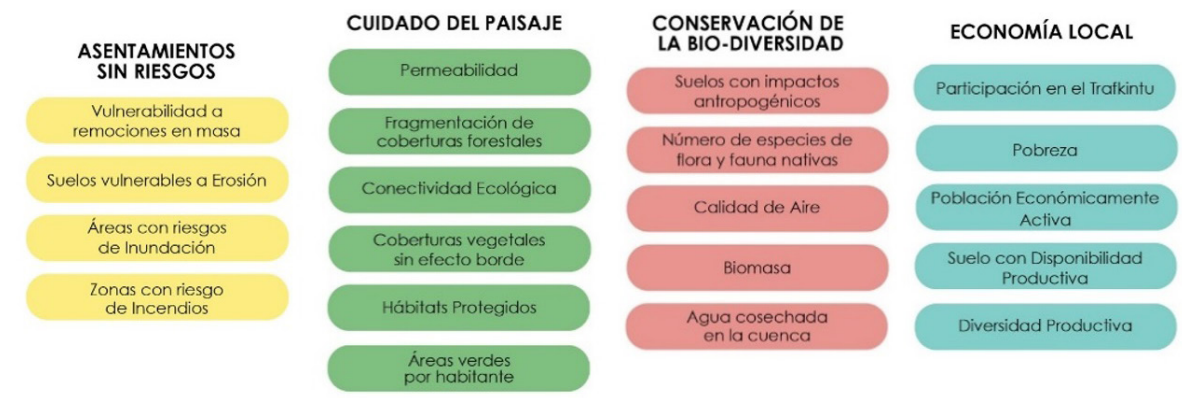

Figura 8. Cuatro indicadores de segunda generación utilizados para el análisis del paisaje de Arauco. Fuente:

Elaboración propia con base en Carrasco et al. (2013)

Figure 8. Four second generation indicators for the Arauco landscape analysis. Source: Own elaboration based on Carrasco et al. (2013)
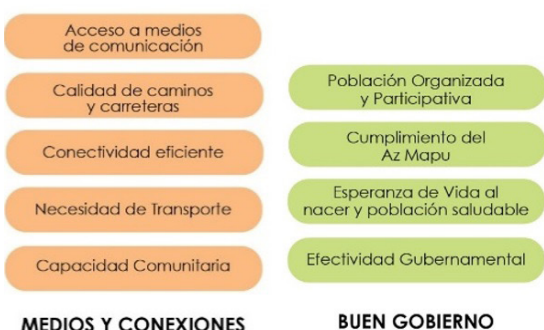

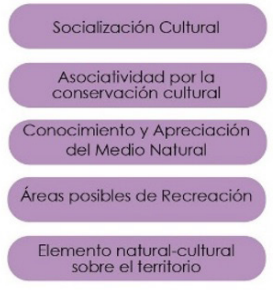

HERENCIA CONSERVADA

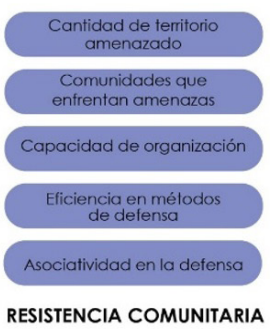

RESISTENCIA COMUNITARIA

Figura 9. Cuatro indicadores de segunda generación propuestos por el autor para el paisaje de Arauco. Fuente: Elaboración propia (2017)

Figure 9. Four second generation indicators proposed for the Arauco landscape analysis. Source: Own elaboration 
Tabla 1

Operacionalización del índice de cuidado del paisaje. Indicador de segunda generación empleado en la investigación. Fuente: Elaboración propia con base en Carrasco et al. (2013)

Table 1

Maintaining the landscape index operationalization. Second generation indicator used in this research. Source: Own elaboration based on Carrasco et al. (2013)

\begin{tabular}{lllllllll}
\hline & $\begin{array}{l}\text { Permeabilidad } \\
\text { del Paisaje }\end{array}$ & Fragmentación & $\begin{array}{l}\text { Conectividad } \\
\text { Ecológica }\end{array}$ & $\begin{array}{l}\text { Áreas sin } \\
\text { Efecto } \\
\text { Borde }\end{array}$ & $\begin{array}{l}\text { Áreas } \\
\text { Protegidas }\end{array}$ & $\begin{array}{l}\text { Áreas Verdes } \\
\text { por Habitante }\end{array}$ & TOTAL & Normalización \\
\cline { 2 - 9 } & & 3 & 1 & 5 & 7 & 5 & 21,00 & 0,32 \\
Permeabilidad del Paisaje (IP) & 0,33 & & 0,33 & 3 & 3 & 5 & 11,66 & 0,14 \\
Fragmentación (IF) & 1 & 1 & & 3 & 7 & 5 & 17,00 & 0,29 \\
Conectividad Ecológica (ICE) & 0,20 & 0,33 & 0,33 & & 1 & 3 & 4,86 & 0,10 \\
Áreas sin Efecto borde (AsEB) & 0,2 & 0,14 & 1 & & 1 & 2,61 & 0,09 \\
Áreas Protegidas (AP) & 0,14 & 0,33 & 0,20 & 0,33 & 1 & & 1,93 & 0,06 \\
Áreas Verdes por Habitante (AVU) & 0,20 & 0,2 & & & & TOTAL & 59,06 & 1 \\
& & & & & & & & \\
\hline
\end{tabular}

$\mathrm{CP}=0,32 *(\mathrm{IP})+0,14 *(\mathrm{IF})+0,29 *(\mathrm{ICE})+0,10 *(\mathrm{AsEB})+0,09 *(\mathrm{AP})+0,06 *(\mathrm{AVU})$

Según Quiroga (2007, p .19), los indicadores de tercera generación son instrumentos transversales y sinérgicos que surgen con los dos grupos previos y "en una o pocas cifras, nos permiten tener un acceso rápido a un mundo de significados mucho mayor, en los cuales esté incorporado lo económico, social y ambiental en forma transversal y sistemática" En este ejercicio se agruparon los 8 indicadores de segunda generación para formar un instrumento llamado Índice de Sustentabilidad del Paisaje de Arauco (ISPA). La ecuación de este índice se realizó de la misma manera que en los indicadores de segunda generación con el método PAJ, por medio de un análisis de importancia desde la perspectiva del autor. En la tabla 2 se presentan los indicadores secundarios que visualizan la importancia de uno por encima del otro en una escala de 7, 5, 3 y 1 donde 7 es mucho más importante y 1 es igual de importante. Se normalizaron los totales para obtener una cifra oscilante final entre 0 y 1 . La figura 10 muestra el ISPA como un esquema de análisis de las dimensiones abordadas en esta investigación.

Tabla 2

Operacionalización del índice de cuidado del paisaje. Indicador de tercera generación empleado en la investigación. Fuente: Elaboración propia con base en Carrasco et al. (2013)

Table 2

Landscape sustainability index operationalization. Third generation indicator used in this research. Source: Prepared by the author on the basis of Carrasco et al. (2013)

\begin{tabular}{|c|c|c|c|c|c|c|c|c|c|c|}
\hline & $\begin{array}{l}\text { Cuidado del } \\
\text { Paisaje }\end{array}$ & $\begin{array}{l}\text { Medios y } \\
\text { Conexiones }\end{array}$ & $\begin{array}{l}\text { Herencia } \\
\text { Conservada }\end{array}$ & $\begin{array}{l}\text { Economía } \\
\text { Local }\end{array}$ & $\begin{array}{l}\text { Buen } \\
\text { Gobierno }\end{array}$ & $\begin{array}{l}\text { Conservación } \\
\text { de la Bio- } \\
\text { diversidad } \\
\end{array}$ & $\begin{array}{l}\text { Resistencia } \\
\text { Comunitaria }\end{array}$ & $\begin{array}{l}\text { Asentamientos } \\
\text { sin Riesgos }\end{array}$ & TOTAL & Normalización \\
\hline $\begin{array}{l}\text { Cuidado del } \\
\text { Paisaje (CP) }\end{array}$ & & 7 & 7 & 3 & 3 & 1 & 7 & 3 & 31 & 0,25 \\
\hline $\begin{array}{r}\text { Medios y } \\
\text { Conexiones } \\
(\mathrm{MyC})\end{array}$ & 0,14 & & 3 & 1 & 0,20 & 0,14 & 3 & 0,33 & 7,81 & 0,06 \\
\hline $\begin{array}{r}\text { Herencia } \\
\text { Conservada }(\mathrm{Hc})\end{array}$ & 0,14 & 0,33 & & 0,33 & 0,20 & 0,20 & 3 & 0,20 & 4,40 & 0,04 \\
\hline $\begin{array}{r}\text { Economía Local } \\
\text { (El) }\end{array}$ & 0,33 & 1 & 3 & & 0,33 & 0,20 & 0,33 & 0,20 & 5,39 & 0,04 \\
\hline $\begin{array}{r}\text { Buen Gobierno } \\
\text { (Bg) }\end{array}$ & 0,33 & 5 & 5 & 3 & & 0,14 & 3 & 3 & 19,47 & 0,15 \\
\hline $\begin{array}{r}\text { Conservación de } \\
\text { la Bio-diversidad } \\
(\mathrm{Cb})\end{array}$ & 1 & 7 & 5 & 5 & 7 & & 5 & 5 & 35 & 0,28 \\
\hline $\begin{array}{r}\text { Resistencia } \\
\text { Comunitaria (Rc) }\end{array}$ & 0,14 & 0,33 & 0,33 & 3 & 0,33 & 0,20 & & 5 & 9,33 & 0,07 \\
\hline \multirow[t]{2}{*}{$\begin{array}{l}\text { Asentamiento sin } \\
\text { Riesgos (AsR) }\end{array}$} & 0,33 & 3 & 5 & 5 & 0,33 & 0,20 & 0,20 & & 14,06 & 0,11 \\
\hline & & & & & & & & TOTAL & 113,40 & 1,00 \\
\hline
\end{tabular}

ISPA $=0,25 *(\mathrm{CP})+0,06 *(\mathrm{MyC})+0,04 *(\mathrm{Hc})+0,04 *(\mathrm{El})+0,15^{*}(\mathrm{Bg})+0,28 *(\mathrm{Cb})+0,07 *(\mathrm{Rc})+0,11 *(\mathrm{AsR})$ 


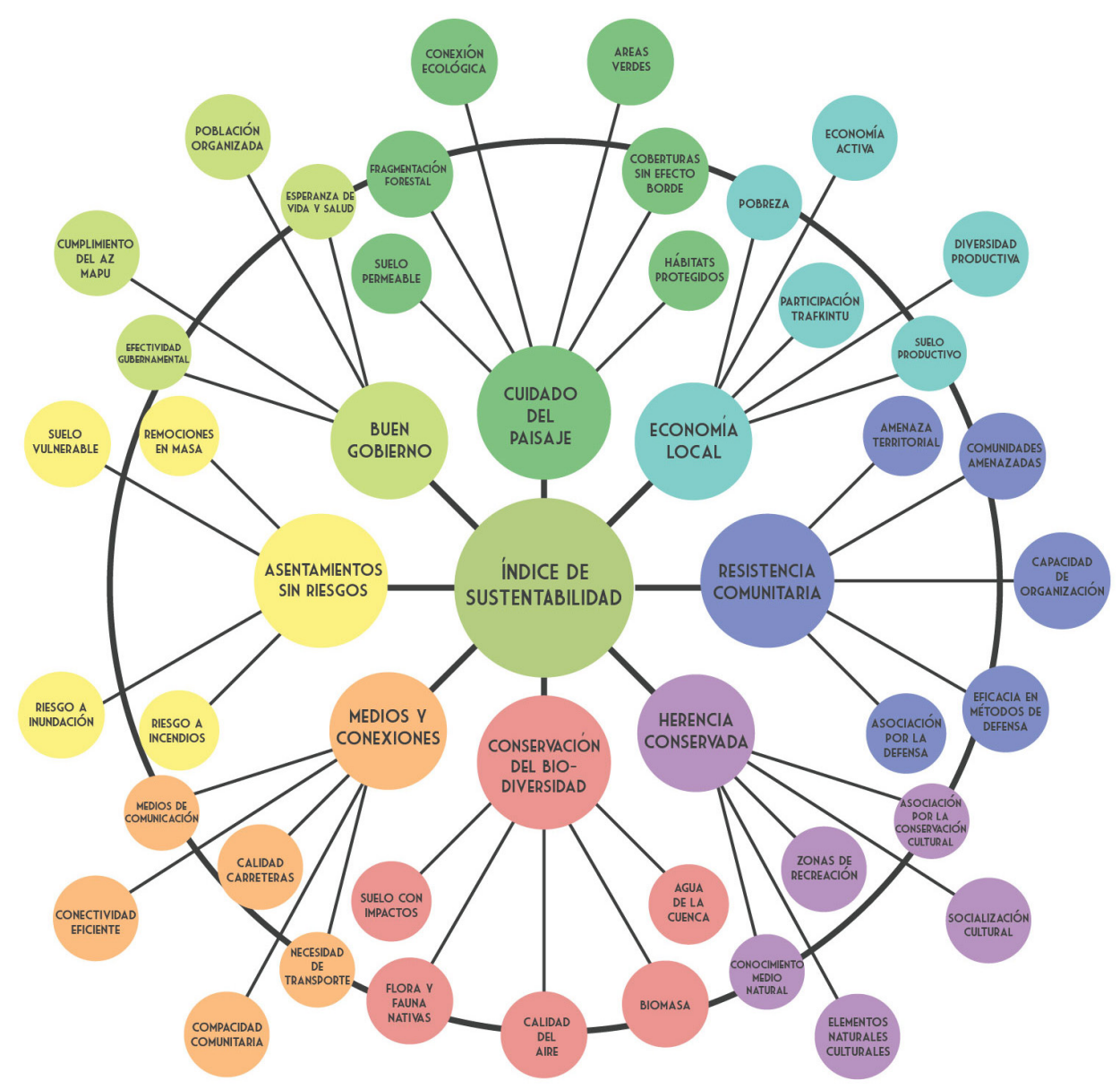

Figura 10. Índice de sustentabilidad del paisaje de Arauco (ISPA), componentes principales, indicadores de primera, segunda y tercera generación. Fuente: Elaboración propia (2017)

Figure 10. Arauco landscape sustainability index, main components, first, econd and third generation indicators. Source: Own elaboration (2017) 


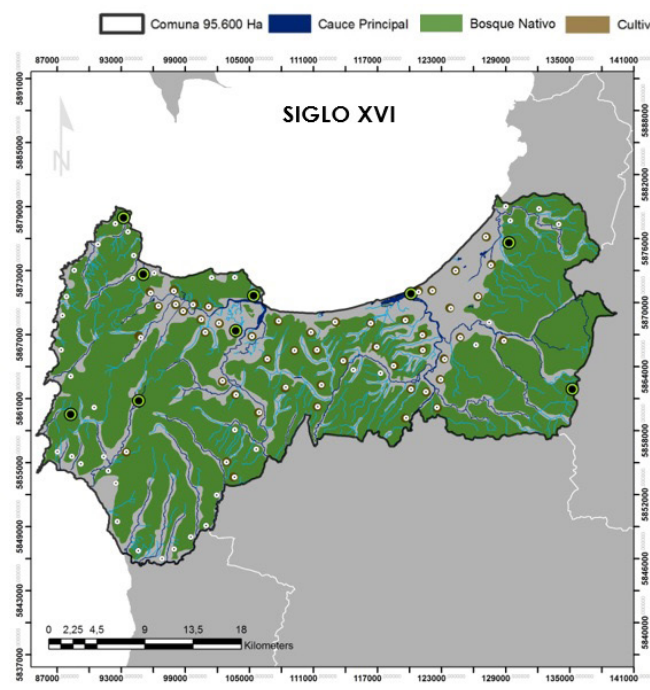

Figura 11. Uso de suelo de Arauco en el siglo XVI. Fuente: Elaboración propia (2017)

Figure 11. Arauco land use in the XVI Century. Source: Own elaboration (2017)

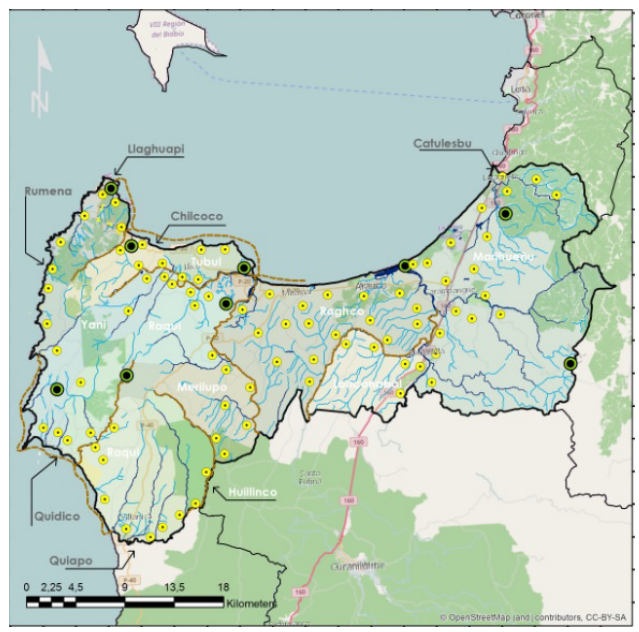

Figura 12. Uso de suelo de Arauco en el siglo XVII. Fuente: Elaboración propia (2017)

Figure 12. Arauco land use in the XVII century. Source: Own elaboration (2017)

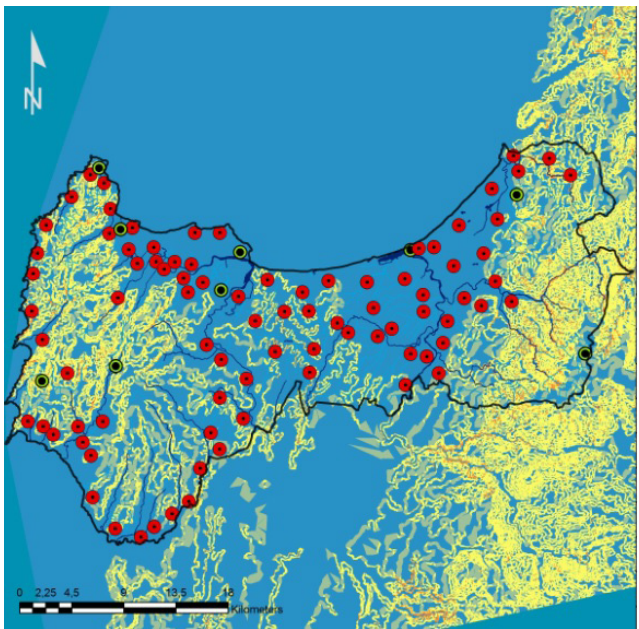

Figura 13 y 14. Organización territorial y riesgos de remociones en masa en Arauco para el siglo XVI. Fuente: Elaboración propia (2017)

Figure $13 \& 14$. Territorial organization and landslides risks in Arauco in the XVI century. Source: Own elaboration (2017) 

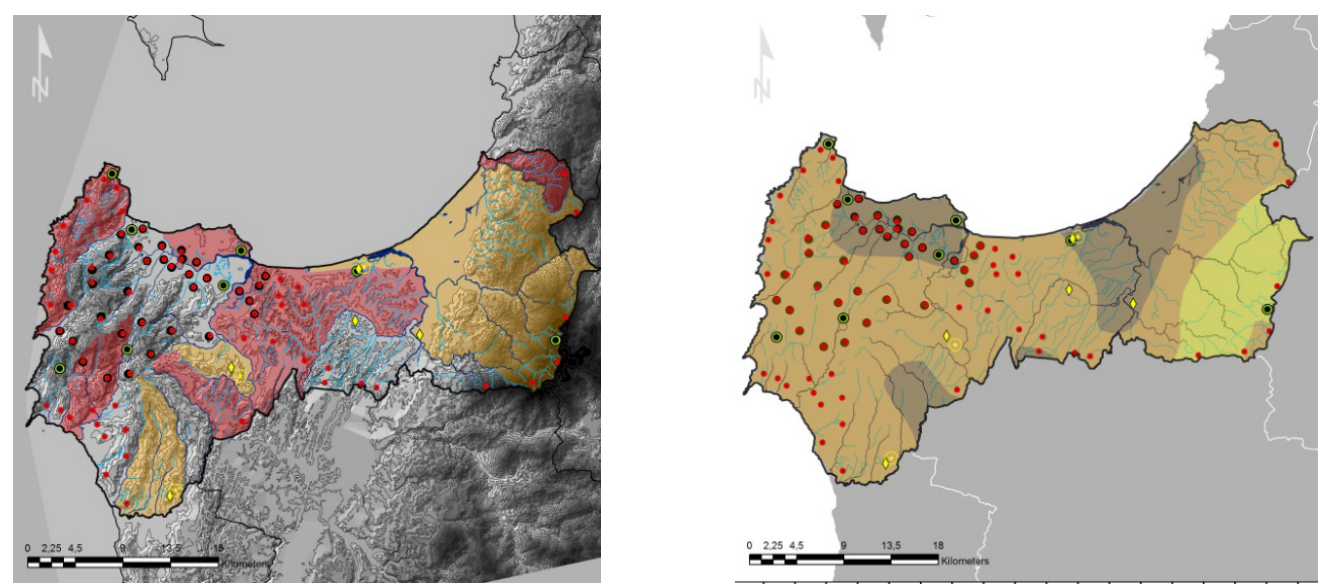

Figura 15 y 16. Organización territorial y riesgos a erosiones en Arauco para el siglo XVII. Fuente: Elaboración propia (2017)

Figure $15 \& 16$. Territorial organization and erosion risks in Arauco in the XVI century. Source: Own elaboration

(2017)

Momentos de estudio en el paisaje de Arauco

Para evidenciar la transformación de Arauco, se empleó la metodología de medición del ISPA en 4 momentos de la historia (Siglo XVI, XVII, 1960 y 2016), cada uno fue elegido en base a los impactos registrados en Arauco por cronistas, historiadores, antropólogos, arqueólogos y sociólogos (Bengoa, 1996; 2007; Caniuqueo, 2013; Chihuailaf, 1999; Correa et al., 2005; Dillehay, 2004, 2011; Huber et al., 2010; Jara, Dresdner y Gómez, 2015; Martínez, 2013; Mella, 2007; Navarro, 1998; Nazif et al., 2014; Seguel, 2003; Toledo, 2006; Torres, 2000 y 2003; Vargas, 2014; Zavala \& Dillehay, 2010; Zelada \& Park,

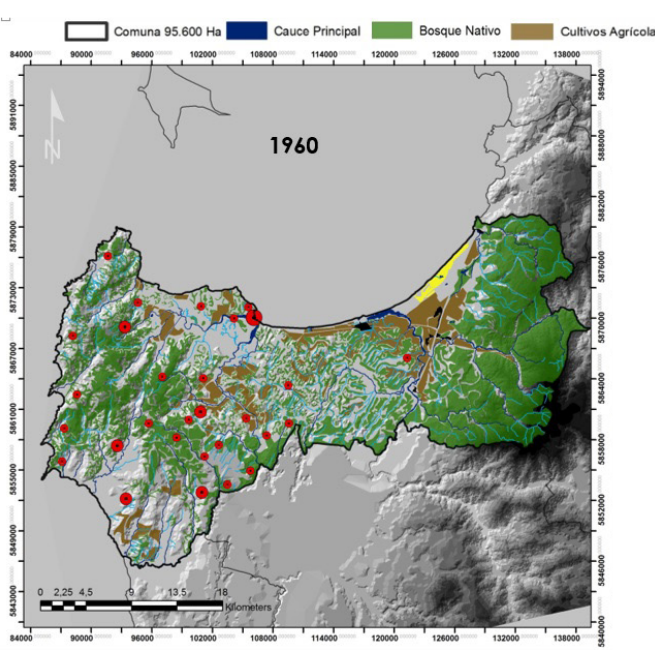

Figura 17. Uso de suelo de Arauco en el año 1960. Fuente: Elaboración propia (2017)

Figure 17. Arauco land use in 1960. Source: Own elaboration (2017)

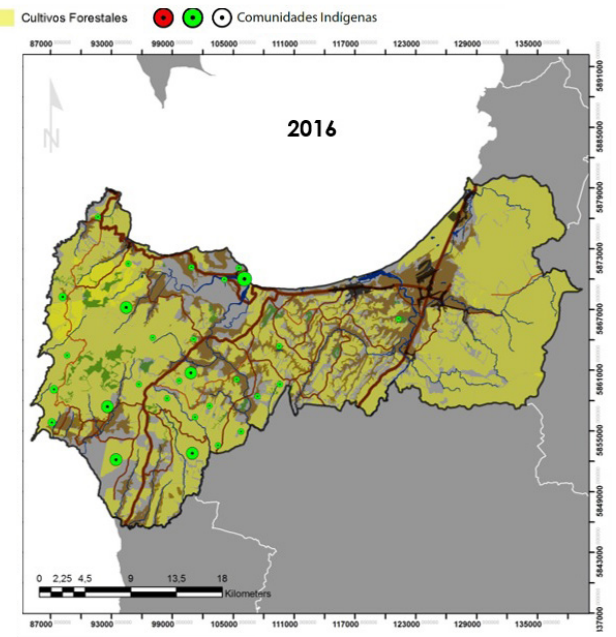

Figura 18. Uso de Suelo de Arauco en el año 2016. Fuente: Elaboración propia (2017)

Figure 18. Arauco Land Use in 2016. Source: Own elaboration (2017) 

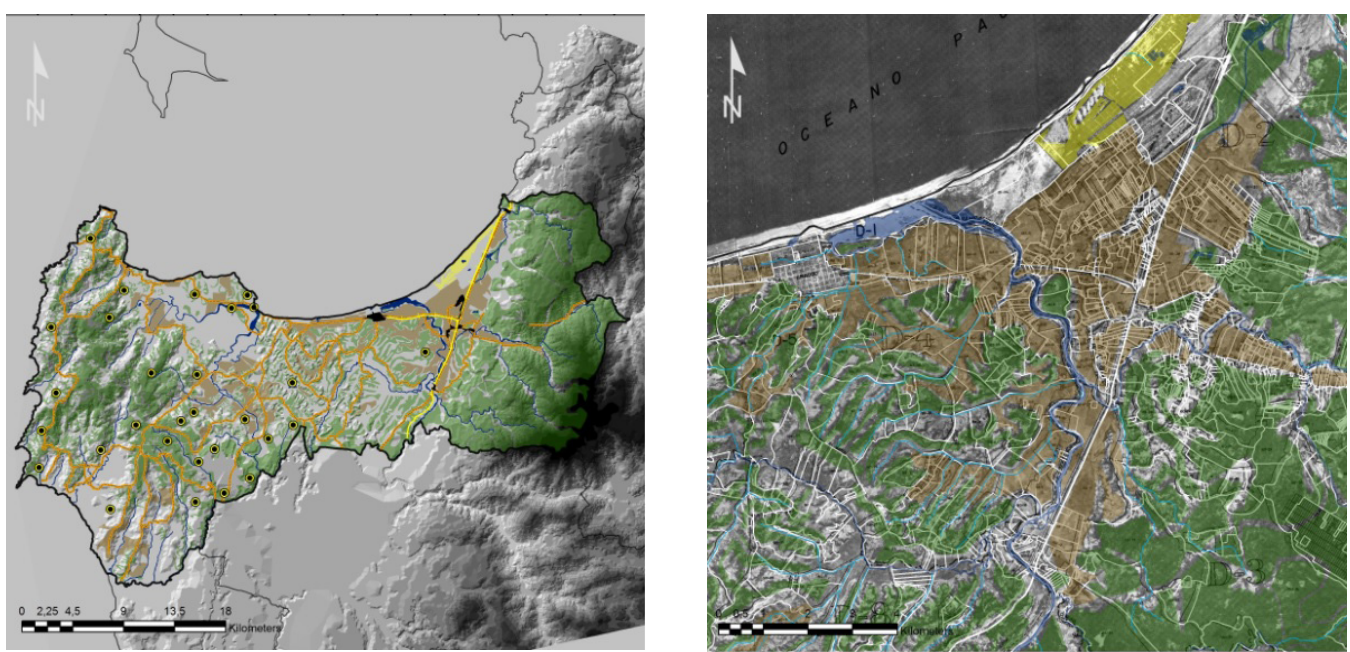

Figura 19 y 20. Conectividad y división del suelo en Arauco para 1960. Fuente: Elaboración propia (2017)

Figure $19 \& 20$. Connectivity and land division in Arauco in 1960. Source: Own elaboration (2017)
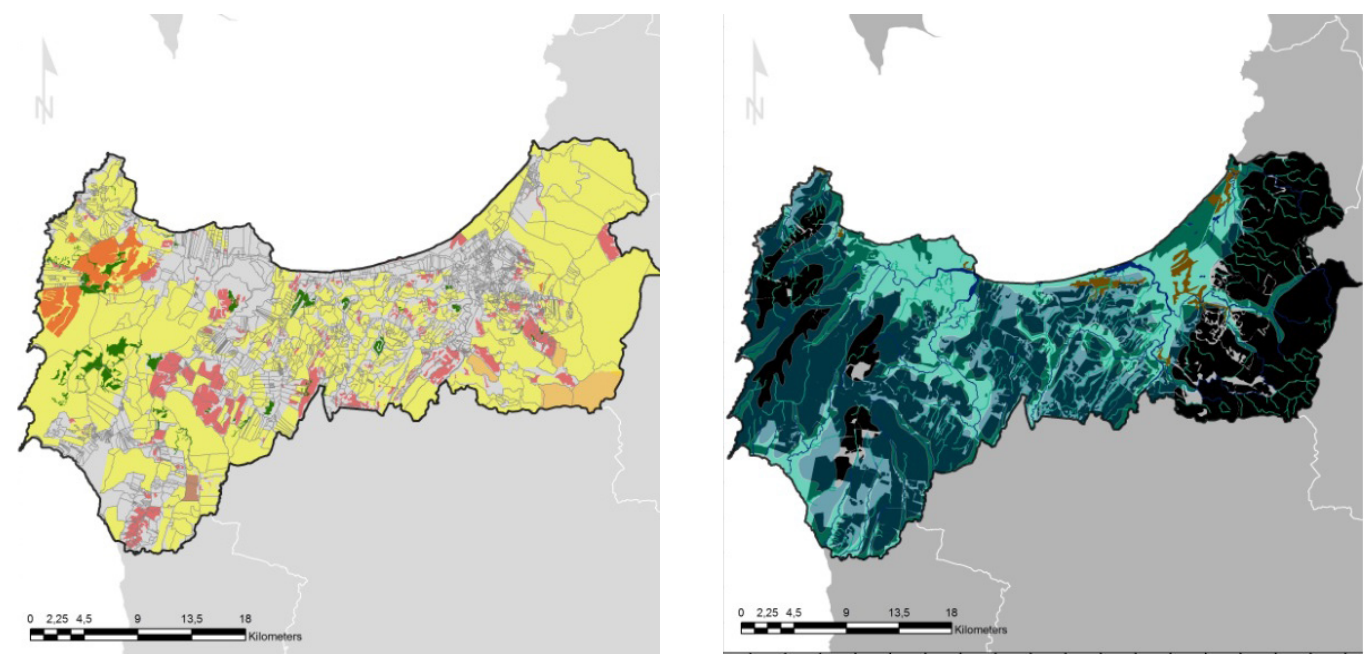

Figura 21 y 22. División del suelo y Vulnerabilidad de acuíferos en Arauco para 2016. Fuente:

Elaboración propia (2017)

Figure $21 \& 22$. Land division and aquifer vulnerability in Arauco in 2016. Source: Own elaboration (2017) 
2013). La mayoría de estos documentos existían en calidad de relato y texto, mas no como referencias exactas, mapas, estadísticas, entre otros, lo que demandó una sistematización de documentos para los primeros dos períodos. Con las referencias se construyeron escenarios hipotéticos para ser evaluados con el ISPA. En las figuras 11, 12, 13, 14, 15 y 16 se presentan las cartografías proyectadas del Siglo XVI y XVII.

Los primeros registros cartográficos de Chile de orto-fotos son de 1960, con lo que se realizó un análisis territorial más preciso (figuras 17, 18, 19, 20, $21 \mathrm{y}$ 22), además que ya existía información estadística para consultar en temas de población, instituciones y economía. Otros datos fueron recabados por medio de entrevistas a pobladores de las comunidades indígenas de Arauco (Locobe, Yani, Yani Mapu Lafken, Chilcoco, Marihuen, Quidico y Lenco), esta información fue sistematizada en la metodología encontrada en Canales (2006), sobre indicadores sintéticos. Por último, para el período de 2016 ya existe información suficiente de los 39 indicadores de primera generación, la cual fue consultada en dependencias del CIREN, Ministerio del Medio Ambiente, Servicio Agrícola y Ganadero, Estudios de Línea Base del SEA en Arauco, Municipalidad de Arauco, entre otros.

\section{Resultados}

Los indicadores de primera generación revelaron cantidades fluctuantes en los 4 períodos, que con la aplicación de la ecuación para cada uno de los 8 indicadores de segunda generación (Ver tabla 1), se definieron cifras totales con intervalos de 0 a 1 , mientras más cerca se encontraba la puntuación del 1 , el indicador presentaba una mejor calificación. En la figura 23 se muestran los resultados obtenidos, la mayoría de indicadores evidencia una pérdida gradual durante los cuatro períodos, otros marcan una caída entre el período del Siglo XVII y el año 1960. Los cambios más evidentes se representan en los elementos del patrimonio natural como el indicador del Cuidado del Paisaje y la Biodiversidad, que ha descendido hasta valores por debajo del $25 \%$. Existen indicadores sin tanta fluctuación desde el penúltimo período (1960), como el Buen Gobierno, Medios y Conexiones y Herencia Conservada, aunque sus porcentajes en la actualidad se encuentren por debajo del 50\%. En el caso del Desarrollo Económico Local, tuvo una gran caída desde 1960, debido a la influencia económica en la transformación del uso de suelo.Al tener los resultados parciales, se operó la ecuación del ISPA (Ver tabla 2), resumiendo todos los componentes en el indicador de tercera generación, con una lectura más clara sobre el paisaje mapuche y su evolución en el tiempo. En la tabla 3 se presenta las cifras finales del ISPA, donde llama la atención el período actual (30\%), que en alusión a la tabla anterior se ha visto afectado por los bajos indicadores referentes al medio natural. La figura 24 presenta los propietarios del territorio de Arauco en los 4 períodos de estudio. 


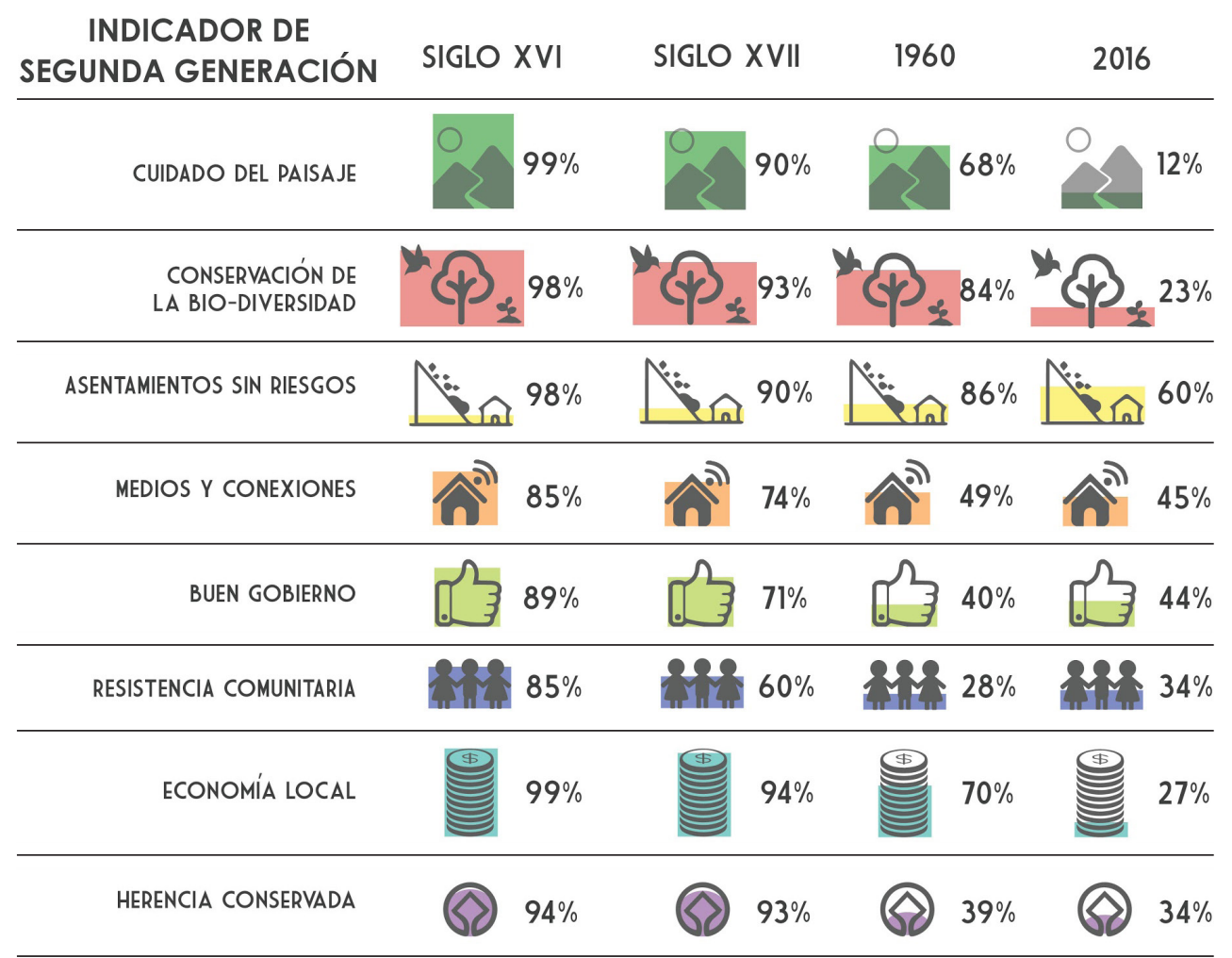

Figura 23. Comparación de todos los indicadores de segunda generación en los cuatro períodos de estudio. Fuente: Elaboración propia (2017)

Figure 23. Second generation indicators comparison between the four periods of study. Source: Own elaboration (2017)

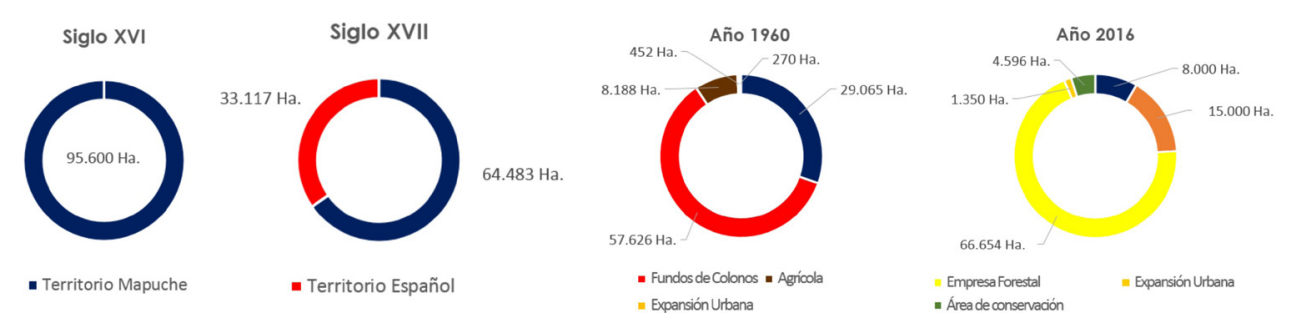

Figura 24. Comparación de todos los indicadores de segunda generación en los cuatro períodos de estudio. Fuente: Elaboración propia (2017)

Figure 24. Second generation indicators comparison between the four periods of study. Source:

Own elaboration (2017) 
Tabla 3

Índice de sustentabilidad del paisaje de Arauco en los cuatro periodos de estudio. Fuente: Elaboración propia (2017)

Table 3

Arauco Landscape Sustainability Index in the four periods of study. Source: Own elaboration (2017)

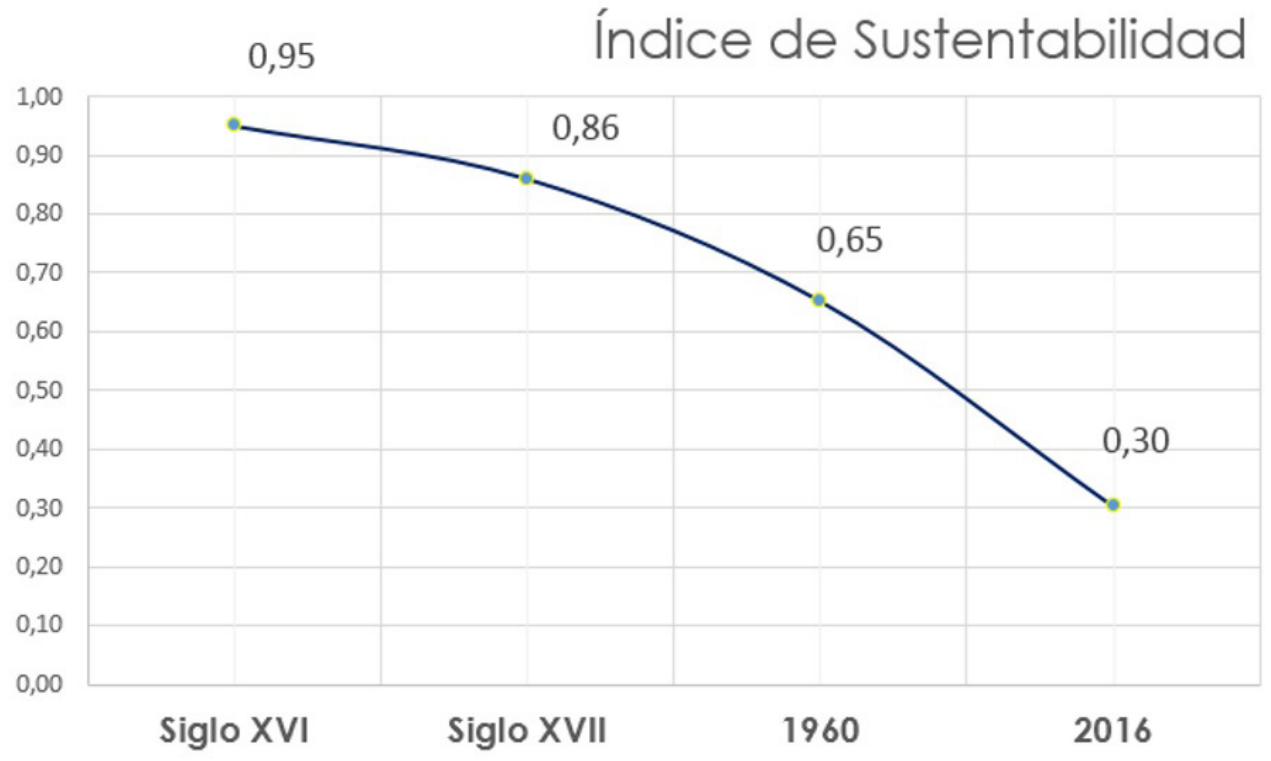

\section{Discusión}

Según Bengoa (1996, p. 27), en Arauco, "la naturaleza abundante en recursos, permitió el desarrollo de un sistema recolector en gran escala", lo que revela los altos índices de biodiversidad que existía previo a las alteraciones en el territorio. A pesar de ser una población con un número elevado (más de un millón de habitantes entre la VII y la $\mathrm{X}$ Región), la forma de vida era adecuada según las necesidades de su entorno. Sin embargo, ese modelo se modificó en el período de la colonia con la agricultura intensiva, reflejándose en la actualidad como un modelo que no sería tan diferente del monocultivo forestal. Otro escenario es la amenaza de la Ley de Pesca (Jara et al., 2015), que permite la pesca de arrastre en zonas artesanales o con planes de manejo.

El reflejo de estas modificaciones al territorio de los mapuches es una pérdida de su relación hombre-naturaleza, donde se da la razón de una alta resistencia en el proceso de recuperación del territorio, ya que existe un vínculo entre el nehuén (fuerzas del universo) y su forma de vida de carácter simbiótico. Bajo ese enfoque, el equilibrio que existe entre el medio ambiente natural con el cultural se reduce por la antropización irresponsable sobre el territorio (Seguel, 2003).

Los instrumentos de planificación territorial como el Plan Regulador Comunal (PRC) se enfoca, generalmente, en el análisis de la zona urbana de una comuna, carecen de un entendimiento de las dinámicas reales de un territorio o paisaje. Según Jaime Pastrana, director de Secplan-Arauco, no existen mecanismos para planificar el crecimiento o el uso de suelo para las áreas rurales, pues el Plan Regulador se enfoca en zonas urbanizadas. En condiciones más responsables, el PRC regularía el crecimiento entendiendo la capacidad soporte y sostenibilidad ambiental, institucional, económica y social de la que dispone.

La metodología empleada para analizar el 
Paisaje de Arauco revela números concisos para comparar las formas de utilizar el territorio, demuestra a través de sus valoraciones, que puede haber decisiones más sostenibles a largo plazo por encima de otras. Además, ofrece el potencial de ser replicada en otros casos y de lograr el entendimiento en la evolución del uso del suelo. Sin embargo, es necesario fortalecer algunos puntos que pueden cuestionar los resultados finales, sobre todo si se trabaja con una sistematización de documentos de texto para representar gráficos en porcentajes, cantidades y estadísticas. Es importante someter los escenarios hipotéticos a la asesoría de especialistas en la materia (arqueólogos, antropólogos, etc.). Se enfatiza que la metodología planteada no puede ser replicada en otro caso de estudio sin antes considerar las diferencias culturales y naturales sobre un territorio específico

\section{Propuesta de imagen objetivo para el paisaje mapuche.}

Esta propuesta se fundamenta con los resultados obtenidos del ISPA, evaluando qué decisiones sobre el territorio permitirían elevar los porcentajes actuales (Ver figura 23). Sin embargo, no responde solamente a un análisis académico-profesional con los resultados obtenidos, sino también a la experiencia cultural lograda con las comunidades indígenas de Arauco. El proceso consistió en la formación de 2 talleres participativos (Mujeres de Yani y Organización Pueblos Originarios en Arauco), y 13 entrevistas a representantes de las comunidades indígenas urbanas y rurales (Locobe, Yani, Yani Mapu Lafken, Chilcoco, Marihuen, Quidico y Lenco). Cada actividad consistió en plasmar las ideas sobre mapas y esquemas sobre el uso ideal del territorio a escala de comunidad y de región, cada uno de los participantes dio a conocer su postura a partir de sus creencias, filosofía y proyección. A lo largo de las entrevistas y talleres se dejó ver un lenguaje que se encuentra compartido tanto en los registros científicos como en las comunidades actuales, lo que confirm la proyección de esta cultura ancestral.

La figura 25 presenta el patrón de asentamiento a escala de comunidad, confeccionada por medio de distintos esquemas y bosquejos. Se consideraron aspectos como la percepción cíclica del territorio, la interacción entre el medio construido y el medio natural. El esquema refleja la unidad básica para una comunidad mapuche, conformada entre 10 y 15 familias, en el cual tiene una distribución porcentual a través de 4 usos importantes de suelo: vivienda, cultivo para siembra (un cuarto del territorio por año), forraje (para alimentación de animales de consumo) y bosque nativo.

Se resume la cantidad de territorio que los mapuches considerarían suficiente lo que estaría vinculado al origen de cada comunidad y la ocupación de los antepasados. Se cuantificaron las hectáreas necesarias a escala de comunidad, familia y persona, con lo que se muestra en la tabla 4.

Según el promedio recabado, una comunidad que cuenta con un número aproximado de 15 familias necesita como mínimo 450 hectáreas, del cual el 50\% de ese territorio es destinado para bosque nativo, el $20 \%$ para cultivo, $21 \%$ para praderas en la crianza de animales y 0,09 en vivienda (terreno cercado con establo, granero, habitaciones, etc.). El análisis por persona consiste en 5 hectáreas, lo que podría contradecir la proyección de sustentabilidad si se compara con el indicador de Huella Ecológica ${ }^{1}$. Sin embargo, para calcular la cantidad real del territorio que sería usado por el mapuche es necesario hacer lo siguiente:

Ha. / Persona: 5 Ha. - 2,50 (B. Nativo) - 0,77 (3/4 del cultivo) $=1,7 \mathrm{Ha}$.

1 Consultado en http://www.footprintnetwork.org/en/index.php/GFN/page/footprint_basics_overview/ 


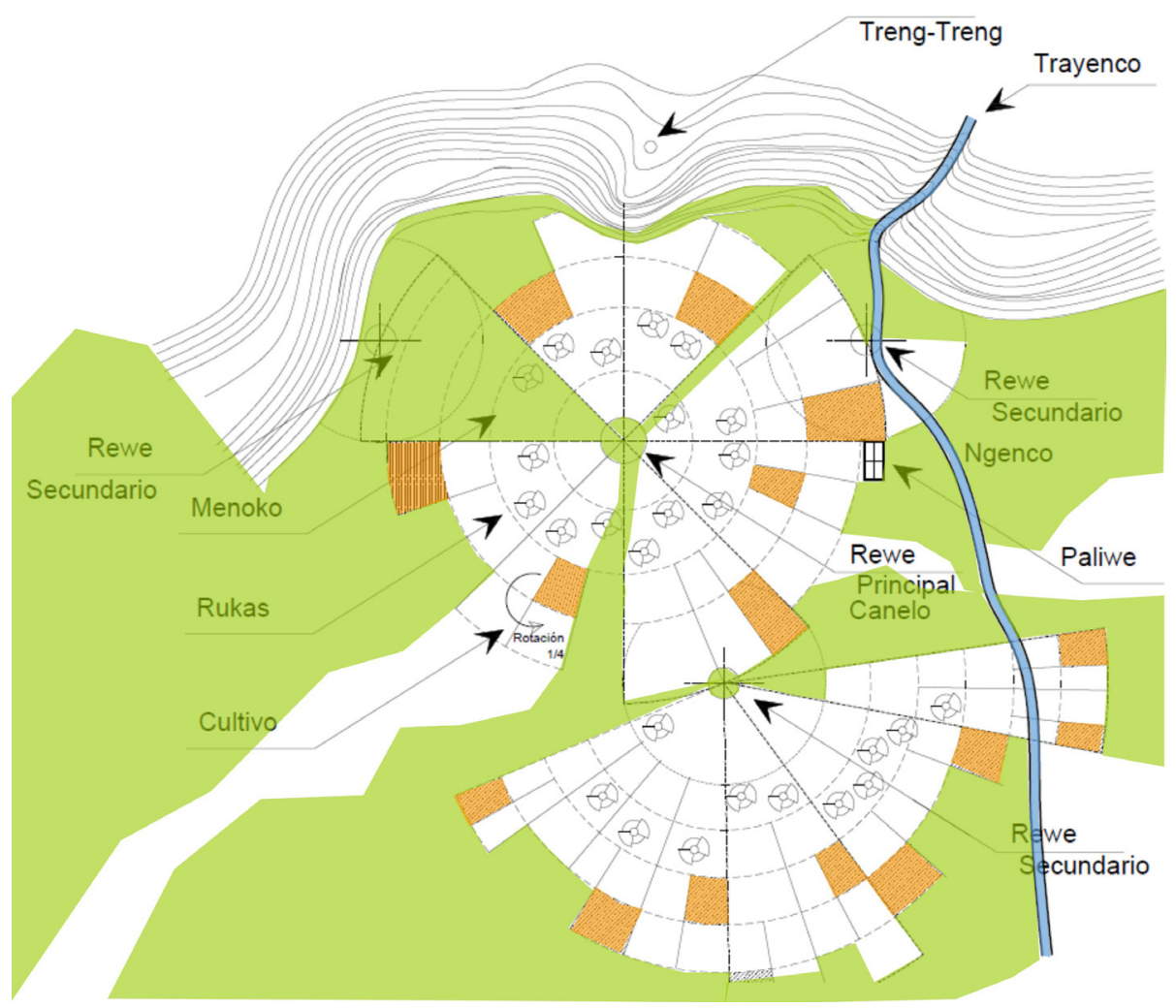

Figura 25. Esquematización del patrón de asentamiento para una comunidad mapuche. Fuente: Elaboración propia en resultado a la interpretación de esquemas y opiniones de pobladores mapuches de Arauco (2017)

Figure 25. Settlement pattern diagram for a mapuche community. Source: Own elaboration based on the interpretation of schemes and opinions by the mapuche inhabitants in Arauco (2017)

Tabla 4

Cantidades de territorio necesario para los mapuches a escala de comunidad, familia y persona.

Fuente: Elaboración propia (2017)

Table 4

Amounts of territory needed for the Mapuche in community, family and person scale. Source: Own elaboration (2017)

\begin{tabular}{lccccc}
\hline & Hectáreas & B. Nativo & Cultivo & Animales & Vivienda \\
\cline { 2 - 6 } Por comunidad (15 fam.) & 450 & 225 & 91,50 & 94,50 & 39 \\
Por familia (6 prom) & 30 & 15 & 6,10 & 6,30 & 2,60 \\
Por persona & 5 & 2,50 & 1,02 & 1,05 & 0,43 \\
\hline
\end{tabular}


El valor final sería menor a 1,8 como espacio en hectáreas máximo de biocapacidad de la tierra (Collis \& Flynn, 2015).

Con el cálculo del uso de suelo por persona, familia y comunidad se obtuvo la base para el trazo de la propuesta de imagen objetivo en la comuna de Arauco, con distintas experiencias compartidas en diferentes contextos se propuso un acercamiento sobre el paso que debería tomar esta comuna en la planificación del paisaje. Se redefini la posición del espacio construido en 4 zonas urbanizadas compactas a diferencia del escenario actual definido por 7. La relocalización también responde a zonas con riesgos constantes de inundación por tsunami o desborde de ríos. Las vías de comunicación entre los centros no solamente se plantean terrestres sino también lacustres, recuperando las rutas ancestrales en tiempos prehispánicos. Alrededor de los centros urbanos se propone el uso de suelo en agroecología, permitiendo producir la alimentación necesaria para la población dentro de la misma cuenca sin poner en riesgo la permanencia del recurso edáfico
Existe la opción de mantener los cultivos forestales en la zona oriente de la comuna en un área más reducida que la actual, dispuesta en zonas de mayor soleamiento y afuera de los fondos de quebrada para el resguardo de esteros (figura 26)

\section{Conclusiones}

Este documento evidencia el patrimonio intangible de los mapuches en sus modos de ocupación, el vínculo con su medio natural, la responsabilidad sobre el correcto uso del entorno a través de sus sistemas de agricultura, intervenciones de bajo impacto al paisaje, conservación del bosque nativo para garantizar la fuente de servicios básicos, distribución equitativa del territorio y la convivencia en los esteros como medios de comunicación y transporte a nivel regional en el contexto de Arauco, que hasta el momento carecía de una contextualización y graficación. Por medio de la metodología propuesta, se tuvo una lectura del paisaje desde el Siglo XVI hasta en la actualidad, evidenciando la pérdida del paisaje Mapuche. El propósito de esta investigación ha sido el

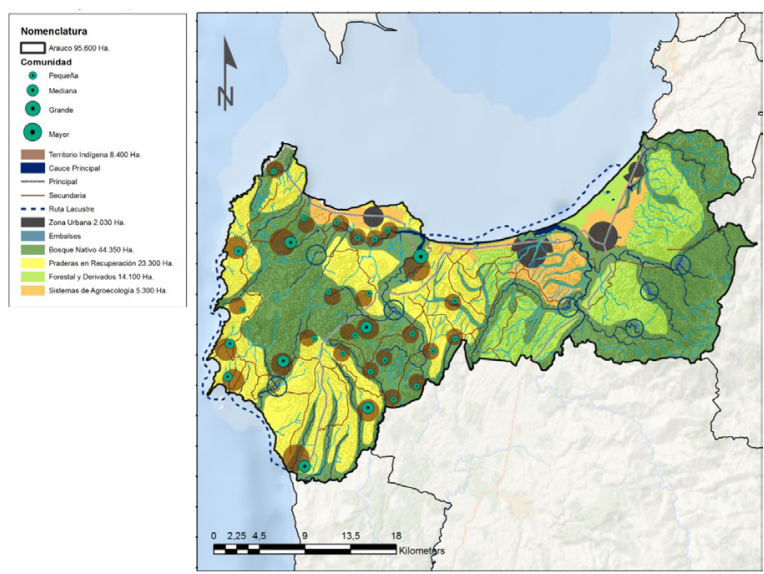

Figura 26. Propuesta de imagen objetivo para el paisaje mapuche. Fuente: Elaboración propia en resultado a partir de resultados obtenidos con el índice de sustentabilidad del paisaje de Arauco y los talleres y entrevistas con las comunidades mapuches de Arauco (2017)

Figure 26. Proposal of the ideal image of the mapuche landscape. Source: Own elaboration based on the results obtained with the Arauco landscape sustainability index and the workshops and interviews with the Arauco mapuche community (2017) 
analizar la sustentabilidad de Arauco desde el conocimiento Mapuche, dejando por medio de los resultados, que el desarrollo de la comuna no es sostenible a futuro y no necesariamente por la pérdida del territorio mapuche, sino también ligado a la falta de identidad que impulsa la globalización con estrategias de desarrollo fuera de un contexto cultural-natural. Con esto se hace la aclaración que el propósito de este trabajo no ha sido con la intención de crear un neo-indigenismo como lo describe el uruguayo Carlos López (1999, p.2012), al decir que "apreciar las peculiaridades de las culturas nativas expresadas en el tipo de discursos que sean, no puede ser motivo para considerarlas como un paradigma de perfección axiomática y por tal motivo haya que adoptarlas..." ya que "esa actitud no aporta gran cosa. Está probado.", tampoco la intención ha sido folcklorizar los elementos más representativos de la cultura mapuche como un producto que se puede comerciar y globalizar. En cambio, la finalidad fue recorrer el pasado a través de lo que la historia deja en herencia o patrimonio intangible, sobre una manera de percibir el paisaje de formas más sustentables, que si bien, los Mapuches, estaban carentes de tecnologías avanzadas, a diferencia de otras culturas de la misma época en el otro lado del mundo, seguramente no lo consideraban necesario, pues al mostrar su capacidad de intercambio vía marítima con pueblos de la Polinesia (Ramírez, 2010; Storey et al., 2007) o de su conocimiento sobre el medio natural, no existe lugar a dudas del desarrollo cultural avanzado de este pueblo originario.

\section{Agradecimientos}

El autor agradece la apertura y participación de las comunidades mapuches de Arauco (Locobe, Chilcoco, Lenco, Tubul, Quidico, Marihuén, Yani y Yani Mapu Lafken) para el desarrollo de esta investigación.

\section{Referencias}

Aj Xol Ch'ok, H. R. (2008). Cosmocimientos y prácticas mayas antiguas. Historia mayab'. Serie Oxlajuj baqtun. Guatemala: Asociación Maya Uk'ux B'e.
Arguedas, J. M. (1958). Uku Mayu. Los ríos profundos. Lima: Losada.

Asturias, M. A. (1974). Hombres de Maiz. San José: Editorial Universitaria Centroamericana EDUCA.

Bengoa, J. (1996). Historia del Pueblo Mapuche, Siglo XIX y XX. Santiago de Chile: Ediciones SUR. Recuperado de http://www. sitiosur.cl/r.php?id=124

Bengoa, J. (2007). Historia de los antiguos mapuches del sur. Desde antes de la llegada de los españoles hasta las paces de Quilín. Santiago de Chile: Catalonia. ISBN: 9789568303761

Bustos, V. \& Vergara, N. (2004) Modelos de ocupación temprana en la bahía de Concepción y Golfo de Arauco. Chungará, Revista de Antropología Chilena, 36(1), 283-288. http://dx.doi.org/10.4067/S071773562004000300031

Canales, M. (2006). Metodologías de investigación social. Inducción a los oficios. Santiago de Chile: Editorial LOM. ISBN: 956282-840-9 Recuperado de http://www.galeon. com/alpuche932/metodo1.pdf

Caniuqueo, S. (2013). Dictadura y Pueblo Mapuche 1973 a 1978. Reconfiguración del colonialismo chileno. Revista de Historia Social y de las Mentalidades, 17(1), 87130. Recuperado de http://www.revistas. usach.cl/ojs/index.php/historiasocial/article/ viewFile/1555/1432

Carabias, D., Lira, N. \& Adán, L. (2010). Reflexiones en torno al uso de embarcaciones monóxilas en ambientes boscosos lacustres precordilleranos andinos, zona Centro-Sur de Chile. Magallania (Punta Arenas), 38(1), 87-108. http://dx.doi.org/10.4067/S071822442010000100006

Carrasco, N. (2015). Sandra López Dietz y Luis Nitrihual Valdebenito, Vidas de papel. Negocio de la madera y conflicto intercultural en Chile, Editorial UFRO, Temuco, Chile, 
2014, 140 p. Polis, 40. Recuperado de RO. Recuperado de http://redalyc.org/articulo. oa? id $=30538546024$

Carrasco, C. \& Murtinho, F. (2016). Simbiosis Natural-Cultural: Experiencia educativa del Magíster en Desarrollo Regional y Medio Ambiente. Valparaíso: Universidad de Valparaíso.

Carrasco, C., Hernández, A., Muñoz, A., Catalán, L., Zora, J., Reyes, A., Quispe, J., Fernández, J. \& Goycolea, J. (2013). Propuesta de indicadores de segunda generación. Modelo de sostenibilidad para la cuenca del Estero de Reñaca. Valparaíso: Universidad de Valparaíso.

Casanova, H. (1987). Las rebeliones araucanas del siglo XVIII. Temuco: Ediciones Universidad de la Frontera. https://books.google.com.gt/books/about/ Las_rebeliones_araucanas_del_siglo_XVIII. $\mathrm{html}$ ? id=nmMaAAAAYAAJ\&redir_esc $=\mathrm{y}$

Chihuailaf, E. (1999). Recado confidencial a los chilenos. Santiago de Chile: Editorial LOM. ISBN: 9562822087

Colipán, B. (2008). El trafkintu como práctica cotidiana y de recomposición de la memoria colectiva. Futawillimapu. [sitio web] Recuperado de www.futawillimapu.org/pub/ Trafkintu.pdf.

Collis, A. \& Flynn, A. (2015). The Ecological Footprint. New developments in Policy and Practice. Northampton: Edward Elgar Publishing. ISBN: 9780857936950

Correa, M., Molina, R. \& Yánez, N. (2005). La Reforma Agraria y las tierras mapuches. Chile 1962-1975. Santiago de Chile: LOM Ediciones. ISBN 9562827097

Dirección General de Aguas. Ministerio de Obras Públicas. (2011). Informe de precipitación pluvial y escorrentía para la Provincia de Arauco.
Díaz, A. (2010). En la Araucanía. El Último Parlamento Mapuche de Coz-Coz. Relato de Aurelio Díaz Meza (1907). Revista Chilena de Literatura. Sección Miscelánea. Recuperado de http://repositorio.uchile.cl/bitstream/ handle/2250/123166/En-la-araucania-elultimo-parlamento-mapuche-de-coz-coz. pdf? sequence $=1$

Díaz, A., Pérez, M. V., González, C. \& Simon, J. (2004). Conceptos de enfermedades y sanación en la cosmovisión mapuche e impacto de la cultura occidental. Revista Ciencia y Enfermería, X(1), 9-16. Recuperado de http://www.scielo.cl/pdf/cienf/v10n1/art02. pdf

Dillehay, T. (2004). Monteverde. Un asentamiento humano del pleistoceno tardio en el Sur de Chile. Santiago de Chile: LOM Ediciones. Recuperado de http://www.scielo.cl/scielo.php?script=sci arttext\&pid=S0717-73562005000200015

Dillehay, T. (2011). Monumentos, impero y resistencia en los Andes. El sistema de gobierno mapuche y las narrativas rituales. Antofagasta: Ocho Libros Editorial.

Dowling, J. (1971). Religión, chamanismo y mitologías mapuches. Santiago de Chile: Editorial Universitaria.

Fuentes R. R. (2003). Llaqtaypa harawin =: Poesía de mi pueblo. Lima: Editorial Universitaria. ISBN 10: 9972951626

Garrido, O. (1998). Influencia de la escuela en la pérdida de la identidad cultural, el caso de la educación indígena en la región de la Araucanía. Tarbiya: Revista de Investigación e Innovación Educativa, 19, 7-29. Recuperado de https://dialnet.unirioja.es/servlet/ articulo? codigo $=4785007$

Gazmuri, J. (2013). La politica de los Mapuche de los gobiernos democráticos. Santiago de Chile: Fundación Felipe Herrera. Recuperado de http://www.politicaindigena. org/documentos/La\%20 Politica\%20 Mapuche $\% 20 \mathrm{de} \% 201$ os\%20Gobiernos\%20 
Democraticos, $\% 201 \mathrm{a} \% 20$ Demanda $\% 20$ de $\% 20$ Tierras $\% 20 y \% 201$ os $\% 20$ Nuevos $\% 20$ Desafios.pd

Goicovich, F. (2002). La etapa de la conquista (1536-1598): origen y desarrollo del "estado indómito". Cuadernos de Historia, 22, 53-110. Recuperado de http://repositorio.uchile.cl/ bitstream/handle/2250/134680/La-etapa-dela-Conquista.pdf?sequence $=1$ \&isAllowed $=y$

Goicovich, F. (2004). José Bengoa, historia de los antiguos mapuches del sur. Desde antes de la llegada de los españoles hasta las paces de Quilín. Historia (Santiago), 37(1), 237-241. http://www.redalyc.org/articulo. oa? $\mathrm{id}=33437108$

Gutiérrez, P., Puentes, J. \& Reyes, P. (2012). Pewün Mapu Rauko. Informe de antecedentes históricos en Quiapo. Arauco: Kudawfe Peñi. Recuperado de https://territorioarauco.files wordpress.com/2014/05/pewc3ben-mapurauko-4.pdf

Gavilán, V. (2007). La nación mapuche: puelmapu ka gulumapu. ISBN: 978-9568641-00.

Heidegger, M. (2008). Arte y Poesía. Ciudad de México: Fondo de cultura económica. ISBN: 950-557-124-0. Recuperado de https:// somoslxspiratas.files.wordpress.com/2017/04 arte-y-poesia-de-martc3adn-heidegger.pdf

Huber, A. \& Trecaman R. (2000). Efecto de una plantación de pinus radiata en la distribución espacial del contenido de agua del suelo. Bosque, 21(1), 37-44. https://doi. org/10.4206/bosque.2000.v21n1-04

Huber, A. \& Trecaman R. (2004). Eficienci del uso del agua en plantaciones de pinus radiata en Chile. Bosque (Valdivia), 25(3), 33-43.https://doi.org/10.4067/s071792002004000300004

Huber, A., Iroumé A., Mohr, C., \& Frenê, C. (2010). Efecto de plantaciones de pinus radiata y eucalyptus globulus sobre el recurso agua en la cordillera de la costa de la región del Biobío, Chile. Bosque (Valdivia), 31(3), 219-230. https://doi.org/10.4067/s071792002010000300006

Huenún, J. L. (2013). Ceremonias. Santiago de Chile: Universidad de Santiago de Chile. ISBN: 956-7069-38-7 Recuperado de http:// www.memoriachilena.cl/archivos $2 / \mathrm{pdfs} /$ mc0029809.pdf

Iroumé, A \& Palacios H. (2013). Afforestatio and changes in forest composition affect runoff in large river basins with pluvial regime and mediterranean climate. Journal of Hydrology, 505, 113-125. https://doi.org/10.1016/j. jhydrol.2013.09.031

Jara, M., Dresdner, J. \& Gómez, W. (2015). Derechos colectivos en pesca artesanal y los intercambios en la política pesquera: un análisis de las políticas distributivas. Estudios de Economía, 42(1), 53-78. https://doi. org/10.4067/s0718-52862015000100003

López, C. (1999). Los "Popol Wuj" y sus epistemologías. Las diferencias, el conocimiento y los ciclos del infinito. Quito: Ediciones Abya-Yala. Recuperado de http:// mds.marshall.edu/languages faculty/1/

Margulis, L. (1998). Planeta simbiótico. Un nuevo punto de vista sobre la evolución. Madrid: Debate. ISBN: 84-8306-998-9

Martínez, P. (2013). Una mirada jurídica a 20 años de la Ley indígena en Chile. The Clinic [sitio web]. Recuperado de http://www. theclinic.cl/2013/10/02/una-mirada-juridica-a20-anos-de-la-ley-indigena-en-chile/

Mella, E. (2007). Los Mapuche ante la justicia. Criminalización de la protesta indígena en Chile. Santiago de Chile: LOM Editores. ISBN 10: 9562829057

Merguier, A. M. (1989). Expide Pinochet, como Ley, la pena de muerte de la raza mapuche. Archivo Chile. Historia Político Social - Movimiento Popular. CEME Centro de Estudios Miguel Enriquez [sitio web] Recuperado de http://www.archivochile. 
com/Dictadura_militar/pinochet/sobre/ DMsobrepino80028.pdf

Micelli, M. \& Crespo C. (2011). La geometría entretejida. Revista Latinoamericana de Etnomatemática, 4(1), 4-20.

Moulian, R. \& Gonzalez C., Y. (2005). María Ester Grebe: caminando con los Ngen. Revista Austral de Ciencias Sociales, 9, 3948. Recuperado de http://mingaonline.uach. cl/pdf/racs/n9/art04.pdf

Mora, Z. (2001). Filosofía mapuche, palabras arcaicas para despertar el ser. Concepción: Kushe. ISBN: 956-7124-09-4 Recuperado de https://www.folkloretradiciones.com.ar/ literatura/Mora\%20Penros\%20Ziley\%20 -\%20Filosofia\%20Mapuche.pd

Navarro, X. (1998). Patrimonio arqueológico indígena en Chile. Reflexiones y propuestas de gestión. Temuco: Instituto de Estudios Indígenas. ISBN: 956 - 236 -114 - 4 Recuperado de http://146.83.150.183/ bitstream/handle/10533/90322/ PATRIMONIO\%20ARQUEOLOGICO $\% 20$ I N D I G E N A \% 20 E N \% 20 C H I L E. pdf? sequence $=1$

Nazif, I., Benavides, M. \& Pizarro, N. (2014). Plantaciones y pobreza en comunas forestales. Santiago de Chile: Gerencia Forestal, CONAF. Recuperado de http://www.conaf.cl/wp-content/files mf/1395859632PlantacionesyPobrezaen ComunasForestales.pdf

Núñez, L., Varela, J., Casamiquela, R., Shiappacasse, V., Niemeyer, H. \& Villagran, C. (1994). Cuenca de Taguatagua en Chile: el ambiente del Pleistoceno superior y ocupaciones humanas. Revista Chilena de Historia Natural, 67, 503-519. Recuperado de http://rchn.biologiachile.cl/pdfs/1994/4/ $\mathrm{Nu} \% \mathrm{C} 3 \% \mathrm{~B} 1$ ez_et_al_1994.pdf

Pairican, F. (2014). Malon: La rebelión del movimiento mapuche 1990-2013. Santiago de Chile: Pehuén. ISBN: 978-956-16-0610-4
Paz, O. (1950). El laberinto de la Soledad. Ciudad de México: Fondo de Cultura Económica. ISBN: 84-375-0419-8

Quintanilla, V. \& Morales, M. (2004). Condiciones ambientales que enfrenta la regeneración del bosque nativo norpatagónico, en ecosistemas intervenidos de Chile

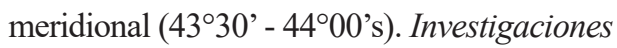
Geográficas, 38, 26-46. https://doi. org/10.5354/0719-5370.2004.27752

Quiroga, R. (2007). Indicadores ambientales $y$ de desarrollo sostenible: avances y perspectivas para América Latina y el Caribe. Santiago de Chile: CEPAL. ISBN: 9789213231005. Recuperado de https://www. cepal.org/es/publicaciones/5498-indicadoresambientales-desarrollo-sostenible-avancesperspectivas-america-latina

Racero-Casarrubia, J. (2008). Determinación de coberturas vegetales $y$ análisis de conectividad en tres microcuencas de la zona cafetera del corregimiento de palmitas. Medellín: Municipio de Medellín. Recuperado de https://es.scribd.com/document/90035146/ Racero-Casarrubia

Ramírez, J. (2010). The Polynesian- Mapuche Connection: Soft and hard evidence and new ideas. Rapa Nui Journal, 24(1), 2933. Recuperado de http://islandheritage.org/ wordpress/wp-content/uploads/2010/06/ RNJ_24_1_Ramirez_Aliaga.pdf

Rosenblitt, J. \& Nazer, R. (2005). Entre el mar y Nahuelbuta: historia del asentamiento humano en Arauco. Archivo Chile. CEME Centro de Estudios Miguel Enríquez [sitio web] Recuperado de www.archivochile. com/Historia_de_Chile/otros_artic/ HCHotrosart0010.pdf

Rueda, S. (2008). Plan especial de indicadores de sostenibilidad ambiental de la actividad urbanística de Sevilla. Barcelona: Agencia de ecología urbana de Barcelona. Recuperado de http://www.ecourbano.es/imag/00\%20 DOCUMENTO\%20ENTERO.pdf 
Saaty, Th. (2008). Decision making with the analytic hierarchy process. International Journal of Services Sciences, 1(1), 83-98. https://doi.org/10.1504/ijssci.2008.017590

Sánchez, J. (2001). El az mapu o sistema jurídico mapuche. Revista CREA, 2, 2839 Recuperado de http://repositoriodigital. uct.cl/bitstream/handle/10925/520/ CREA_03_2001_2_art2.pdf

Seguel, A. (2003). Radiografia al conflicto forestal en el Gulumapu. Antecedentes del conflicto, invasión y consecuencias ocasionadas por empresas madereras en el territorio mapuche. Temuco: Konapewman. Recuperado de http://studylib.es/doc/123596/ radiograf $\% \mathrm{C} 3 \% \mathrm{ADa}$-al-confl cto-forestal-engulumapu

Sharifi, A.; Murayama, A. (2012). A critical review of seven selected neighborhood sustainability assessment tools. Environmental Impact Assessment Review, 38, 73-87 https:// doi.org/10.1016/j.eiar.2012.06.006

Schuschny, A., Soto, H. (2009). Guía metodológica, diseño de indicadores compuestos de desarrollo sostenible. Santiago de Chile: Comisión Económica para América Latina y el Caribe (CEPAL). Recuperado de http://repositorio.cepal.org/bitstream/ handle/11362/3661/1/S2009230_es.pdf

Storey, A., Ramírez, J., Quiroz, D., Burley, D., Addison, D., Walter, R., Anderson, A., Hunt, T., Athens, S., Huynen, L. \& MatissoSmith, E. (2007). Radiocarbon and DNA of a pre-columbian introduction of Polynesian chickens to Chile. Proceedings of the National Academy of Sciences, 104(25), 10.335-10.339 https://doi.org/10.1073/pnas.0703993104

Toledo, V. (2006). Pueblo Mapuche. Derechos colectivos y territorio: Desafios para la sustentabilidad democrática. Santiago de Chile: LOM Ediciones. ISBN: 956-7889-236. Recuperado de http://wrm.org.uy/oldsite/ paises/Chile/libropueblomapuche.pdf
Torres, L. (2000). Diccionario históricogeográfico de la Comuna de Arauco. Hualquén: Trama Impresores. ISBN: 978-956310-083-9

Torres, L (2003). Arauco es Historia. Talcahuano, Chile: Consejo Nacional del Libro y la Lectura. ISBN: 9562917363

Torres-Salinas, R., Azócar, G., Carrasco, N., Zambrano-Bigiarini, M., Costa, T. \& Bolin, B. (2016). Forestry development, water scarcity and the mapuche protest for environmental justice in Chile. Ambiente \& Sociedade, 19(1), 121-144. http://www.scielo.br/scielo. php?script=sci_arttext\&pid=S1414-753X201 $6000100008 \& \operatorname{lng}=$ en\&tlng=en

Ugent, D., Dillehay, T. \& Ramírez, C. (1987). Potato remains from a late Pleistocene settlement in southcentral Chile. Economic Botany, 1 (41), 17-27. https://www.jstor. org/stable/4254928?seq=1\#page_scan_tab_ contents

Vargas, M. (2014). Conflictos Territoriales actuales en el Aillarehue de Arauco: etnografia de aplicación del derecho indígena en tres conflictos vividos por las comunidades mapuche Küdawfe Peñi y Sucesión Quiñimil (Tesis para optar al título de Antropólogo), Universidad de Concepción. Chile.

Zavala, J. \& Dillehay, T. (2010). El "Estado de Arauco" frente a la conquista española: estructuración sociopolítica y ritual de los Araucano-Mapuches en los valles Nabuelbutanos durante los siglos XVI y XVII. Chungara, Revista de Antropología Chilena, 42(2), 433-450. http://dx.doi.org/10.4067/ S0717-73562010000200007

Zelada, S. \& Park, J. (2013). Análisis crítico de la Ley Lafkenche (No. 20.249). El complejo contexto ideológico, jurídico, administrativo y social que dificulta su aplicación. Universum, 28(1), 47-72. http://dx.doi.org/10.4067/S071823762013000100004. 